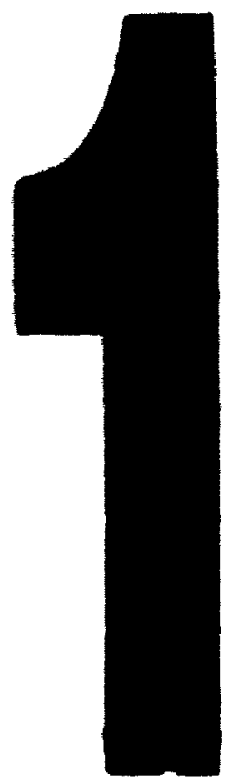

PM-1 3',$\times 4$ PHOTOGRAPHIC MICROCOPY TARGET NBS 1010a ANSI/ISO \#2 EOUIVALENT

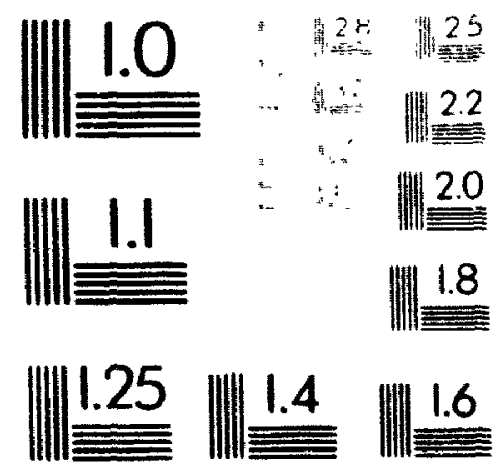

PRECISIONSM RESOLUTION TARGETS 
MEDICAL EDUCATION REFORM IN CANADA

by

Patricia Rutherford, B.A

\begin{abstract}
A thesis submitted to the Faculty of
Graduate studies and Research in partial fulfillment

of the requirement for the degree of

Master of Arts

in Canadian studies
\end{abstract}

\author{
Carleton University \\ ottawa, ontario \\ August 26,1996 \\ 1990, Rutherford
}


The author has granted an irrevocable non-exclusive licence allowing the National Library of Canada to reproduce, loan, distribute or sell copies of his/her thesis by any means and in any form or format, making this thesis available to interested persons.
L'auteur a accordé une licence irrévocable et non exclusive permettant à la Bibliothèque nationale du Canada de reproduire, prêter, distribuer ou vendre des copies de sa thèse de quelque manière et sous quelque forme que ce soit pour mettre des exemplaires de cette thèse à la disposition des personnes intéressées.

L'auteur conserve la propriété du droit d'auteur qui protège sa thèse, Ni la thèse ni des extraits substantiels de celle-ci ne doivent être imprimés ou autrement reproduits sans son autorisation.

ISBN $\quad 0-612-19451-5$ 


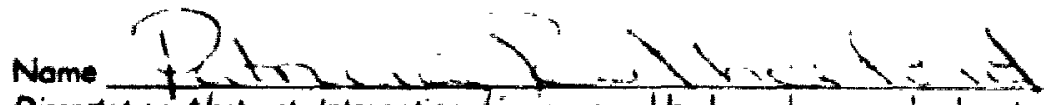

Dissentotion Abstrocts International is arranged by broad general subject categories Please selext the one sutyeat which most neorly describes the content of your dissertation Enter the corresponding four digit code in the spaces provided

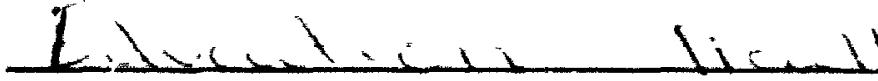

susect reph

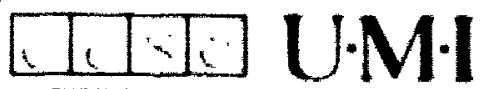

SUEtect roof

\section{Subject Conegories}

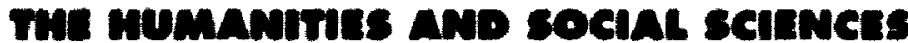

Architecture

Ant History

Cinemo

Fine firts

intormahcis Science

tournalism

Librory Sctence

Mass Communicutions

Muse

Speech Communication

Theoter

\section{Exariom}

Admirnstrotion

Adult and Contruing

Agricutur of

Art

Bilangual and Muliculiural Business

Community Coliege

Early Chidhood

Elementary

Finance

Guidonce and Counseling

Heolth

Higher

Mistory of

industriol

Mothematiss

Musec

Philosophy of

Physted

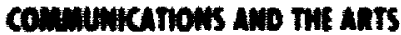

Curreculum and instruchion

Home Esonomic:

Language and Literature
0729

0377

$\operatorname{lom}_{0 \rightarrow 8}$

0357

0723

0391

3300

i. 08

0413

0515

95ia

0516

0517

0688

0275

$077 ?$

0518

0524

0680

0745

0745
0520

0278

0521

5279

1280

3522

0523
Reoding

Reisgous

scinces

Soual Scences

Socidouy of

Speciol

Troocher Trating

Texhnotoy.

Vorotiond

LAHGUAGE, UTERATURE ANO unctustics

Longiroge

Anciant

Anguistics

Moder'

Etetighure

Genera!

Comporative

Med eva

Modern

Africon

Americar

Asson

Conodian (English)

Conodion French)

English

Germoni:

Latin Americon

Middle Enster

Rontance

Slove and Fas Eurbers:

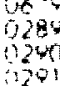

2289

1201

(4)

1294

205

0319

(1)

i) 35

a) 55

tes

1) 312

33

U3i:

ט? 14
Pifcholiogt

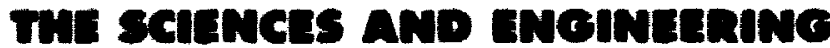

\section{molocical sainces}

Agriculture

Generd

Agronomy

Animal Culture ond

Nutrition

Animal Pathology

Textinology

Forestry and Wildife

Plont Culture

Plant Pothology

Tant Physiology

Range Manogement

Biology

Genero

Anotomy

Brostotistics

Botany

Celt

Ecology,

Eniomology

Mitrobiology

Moleculor

Neuroscience

Oreonography

Physiology

Vetetinary Sxience

Vefietinary

Bisphystes

Gential

0473

0428

0475

0476

035

0478

0479

0480

0817

0777

0746

0306

0287

0308
0309

0309
0379

0329

0353

0369

0793

0410

0307
0317

0416

0.33

0821

0778

0472

0766
0760

thmi sanas

Biogochemilhy

Geochemistry
Geodesy

Geology

Geophysics

Minerdigy

Poleobotany

Poleoecologr

Poleontology

Poleozooloy

Polynology

Physical Goography

Physiral Otoonography

HEATH AND ENVMONMENTAL

satwas

Environmentol Soleties

Heolth Sriences

General

Atrotiology

Chemother opy

Dentistry

Hospital Manogement

Human Develospment

immunotogy

Madicule and Surgery

Mental Healh

$\begin{array}{ll}\text { Nursing } & 0565 \\ \text { Nutrition } & 0570\end{array}$

Obstetrics and Cynecology 0380

Therapy

Ophinalmology

Puthology.

Pharnineotogy

Fhormosy

Physical theropy

Public Heolith

Rodiotogy

030

0,173

0388

1411

0345

9426

995

$147^{2}$

368

14 !

0708

0,00

0300

0972

0350

2769

0,8

$098:$

034
Occupolional trealth and
PHILOSOPHY, ntuelon AND THrology

Patilastit.

Ration

minnsy

Bat

tienty

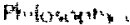

theoly

socin safuces

Amertas: an:

Antionsiandy

At lickentionty

Fhy

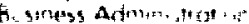

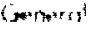

Ax: $2 x y+4=1 ;$

Buminis

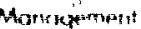

Marketiotis

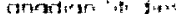

Eextersic

Genciai

Aytutithatgé

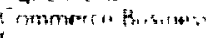

timenter

(1tstomy

toling

faitions

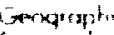

cotoritrikgu

tatsity 
The undersigned recommend to the Paculty of Graduate Studies and Research acceptance of the thesis

"Medical Education Reform in Canada"

submitted by Patricia Rutherford, Hons. B.A. in partial fulfilment of the requirements for the degree of Master of Arts

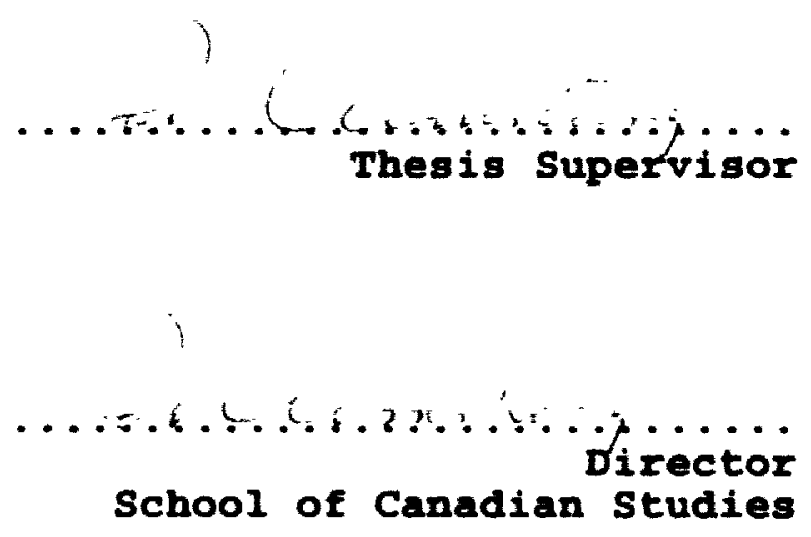

Carleton University

Ottawa, Ontario

August 1996 


\begin{abstract}
This thesis is a critical examination of current and past efforts at reforming medical education in canada. I conclude that the current reform agenda merely :ontinues the longstanding pattern of reform without substantive change that has characterized medical education this century. The medical profession today holds a dominant position in our society that is, in part, related to its control over the content, structure and process of medical education. The profession achieved, and now maintains, its powerful role through its close connection to modern science. I arque that the profession seems unwilling to move beyond the narrowly scientific training that has come to characterize medical education this century. This training best serves the professional interests of physicians, rather than the health care needs of the communities that they serve.
\end{abstract}




\section{ACKNOWLEDGEMENTS}

There are many people who helped me complete this project and I would like to take this opportunity to thank them for their support. First of all, I must thank my supervisor Pat Armstrong. In spite of a hectic schedule, pat has always been generous with her time and support. Her thoughtful advice has guided me successfully through the often frustrating and intimidating process of writing this thesis. Thanks also to the faculty, staff and students of the school of Canadian studies, Carleton University.

To all my friends who have put up with me these past few months, I appreciate the long phone calls and supportive words. In particular, I would like to thank my Thesis support Group who have helped me in countless ways. Thank you Kate Campbel1, Susie Aylard, Lilja Jonsdottir and Denis Poulin. I would also like to thank my parents and my sister Margaret who have always supported and encouraged me in everything that I have done. Thanks also to Angus and Andy for keeping me company through the long days and nights.

Finally, I must acknowledge my best friend, computer technician and chief editor, Michael Mercier. Without you none of this would have been possible. Thank you. 


\section{TABLE OF CONTENTS}

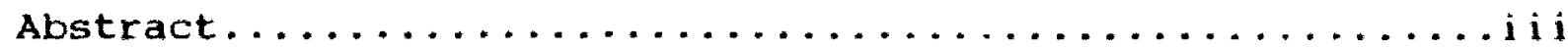

Acknowledgements. . . . . . . . . . . . . . . . . . . . iv

\section{Chapter 1}

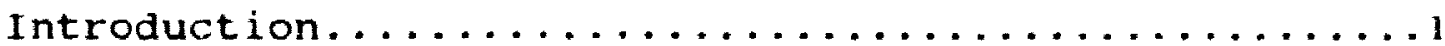

Chapter 2

Theoretical Framework: Medicine as a profession and the Sociology of Medical Education..............

Chapter 3

A History of Medical Education............... 14

Chapter 4

Current Reforms at Canadian Medical Schools.........

Chapter 5

Conclusion...........................

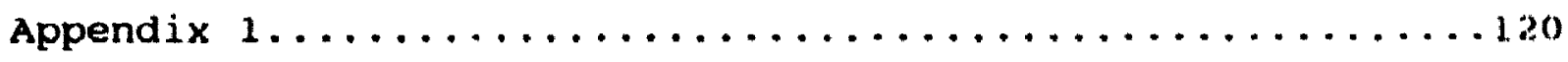

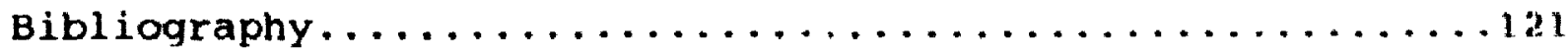


Chapter One

\section{INTRODUCTION}

Medical schools are frequently criticized for graduating physicians with poor communication skills, little compassion and respect for their patients, and narrowly scientific and technological orientations. Medical schools themselves are often regarded as elitist institutions that perpetuate the dominance and control of the medical profession in society, rather than train young doctors to best meet the needs of the communities that they will serve in the future. These criticisms, and many others, are not new. The shortcomings of modern medical education have been well-documented for some time. In November 1988, a seminar on North American medical education was organized to consider how to better educate 'the doctor of tomorrow'. Thirty-four participants, ranging from medical school deans and professors to representatives of medical associations and American government officials, met for three days to discuss how to make medical education more relevant to the demands of current and future medical practice. The document released after the conference included the following "points of general agreement":

Our nation needs doctors with a broader and more sensitive view of the place and role of medicine in the larger society.

Our nation needs doctors who are relationships. We should introduce a 
better blend of humanism and science into our health care institutions and the students they graduate.

Modern physicians should pay more attention to health promotion, disease prevention, and che social, environmental, and emotional factors bearing on health.

Both physicians who graduate and the academic medical institutions that produce them should have a strong sense of social responsibility for the health and medical care rendered in their communities... (quoted in Fox, 1990, 200).

At first glance, these commendable sentiments appear encouraging and supportive of positive change within medical education. Unfortunately, however, these types of formal statements of intent produced by the medical profession and its educators have appeared periodically, and with increasing frequency, over the past one hundred years. For the most part, these documents and meetings have had little or no impact on the nature of medical training in either canada and the United States. In the mid-1980's, The Report of the Project Panel on the General Professional Education of the Physician (The GPEP Report), acknowledged this lack of fundamental change.

A review of past efforts to modify
medical education reveals that most of
the problems identified in the course of
this project are not new. Institutions
intermittently have changed their
curricula, but unfortunately little
progress has been made toward a
fundamental reappraisal of how physicians
are educated (GPEP Report, 1984,8 ).

This pattern of "reform without change" (Bloom, 1988, $294)$ is the most striking theme in the history of medical 
education. Again and aqain, the need to address the shortcomings of our system of medical education is reaffirmed and periodically curricular changes are implemented at medical schools. Yet fundamentally, the process of medical training alters very little. In recent years, particularly since the publication of The GPEP Report, there has yet again been increased interest in re-defining the goals of medical education and in reforming medical school curricula in order to better meet the needs of our changing society. Examining these latest developments, as well as the history of medical education reform, forms the basis of this study.

In essence, the goal of this thesis is to critically assess the implementation of the current canadian medical education reform agenda in light of both the past efforts at reform and the important role that control of medical education plays in maintaining the powerful and privileged position occupied by the medical profession in our society. I arque that the current reform agenda is not radically new or different. The changes being made do not address the fundamental problems of our present system of medical education, but rather serve to reinforce the dominant position of the medical profession in our society. The perennial theme of "reform without change" will be used as a context within which to investigate the current efforts at reform underway at Canadian medical schools. I will be using the literature on professions and the position and role that they play in our 
society as the theoretical framework that informs my analysis. I wili also be drawing considerably on the literature from the field of medical sociology that focuses specifically on medical education and the process of professional socialization.

specifically, in the second chapter I explore the theories of professions and the relationship between professional dominance and control and the institution and process of medical education. The socialization process that occurs during medical training and contributes to the maintenance of the privileqed position of the medical profession is then discussed. The third chapter presents the history of medical education reform in both canada and the United States. The goal of this chapter is to demonstrate the ongoing nature of medical education reform and the failure to implement meaningful, long-term change. In the fourth chapter, I discuss the current reform agenda in Canada. I present four general themes that characterize the changes currently being undertaken and endeavour to relate these to the issues and themes raised in the previous two chapters.

There is a wealth of secondary literature available on all aspects of medical education written by physicians and medical educators, sociologists, psychologists, historians and others. Unfortunately, most of the work focuses largely on the American situation and context and the literature with an explicitly canadian focus is somewhat limited. Although the 
two health care systems are differently funded, the similarities that exist between the American and canadian systems of medical education permit, with some qualifications, the application of American sources to the Canadian context. There is clearly, however, a need for more canadian work to be done on this issue. Therefore, the focus on the current Canadian reform agenda is a unique aspect of this thesis.

The primary work undertaken in this study is based on the documents and reports on medical education published by the profession itself. These range from the 1910 Flexner Report to the recently complete Educating Future Physicians for ontario (EFPO) Project. The sections on current curricular change are based on material that I collected on the thirteen English speaking medical schools in Canada. I used material from University calendars and applicant information brochures. I also wrote to each medical school requesting any information that they could supply me with on their current programs and, in particular, any recently instituted curricular changes. Ten schools responded promptly with very helpful information packages that included published articles, student handbooks and, in some cases, lengthy documents outlining curricular reforms. Despite repeated attempts, three institutions did not respond to my requests for additional information and in those cases, I have used what information that I could gather in the University calendars.

Physicians play an integral role in our health care 
system. As this system adapts to the changing neods and demands of our society, physicians' practice patterns, knowledge and roles must change as well. Our system of medical education must be able to train future physicians to best meet the changing demands of the communities that they will sierve. It is important, therefore, to examine how we train our doctors to ascertain whether today's medical students will possess the skills and abilities to meet the health care needs of our soci,, the next century. It is my hope that this study may contribute to this process. 
Chapter Two

THEORETICAL PRNABNOR: MBDICINE AS A PROFESS;ON AND THE SOCIOLOGY OP MEDICAL BDUCATION

Much has been written on medical education by physicians, historians, psychologists and sociologists. The literature produced by the medical profession concentrates largely on specific aspects of medical school curricula. Sociologists and psychologists, on the other hand, have concerned themselves with issues of socialization; the powerful impact that the curricula, as well as the irstitutions' philosophies and educational environments can have on the students" development, education and practice of medicine. Sociologists have also focussed considerable attention on medicine as a profession and on how this standing has influenced and continues to influence the role that physicians and medicine play in our society.

For the purposes of this thesis, I will use this literature on professions as a framework within which to investigate medical education reform. This general framework then directs my research toward an analysis of the material, produced by medical sociologists, on professional socialization and on the experiences of studerts in medical schools. What follows, therefore, is an overview of the theories of the professions and the debate over the medical profession's changing status in our society. The widely studied socialization process will then be addressed in 
relation to the literature on the professions because of the importance of socialization in the perpetuation of professional power and dominance.

Allopathic physicians and surgeons currently enjoy a monopoly over the provision of medical care in our society; essentially they have an exclusive, state supported right to organize and direct the bulk of medical care. With the emergence of scientific medicine in the nineteenth century, a model of medical practice, based on faith in the scientific method and the notion of specific etiology, developed and expanded its influence in North America. The new scientific medicine gave the so-called "regular" practitioners, medical doctors, an advantage over the other healers that existed at the time. Advances in medical knowledge and practices, such as the development of germ theory and anesthesia, impressed both the public and the state. The scientific method was presented by scientists and the regular practitioners as the on $1 y$ way to advance as a society, to improve health and to alleviate human suffering. The relatively well-organized, politically wellconnected, governing bodies of the regulars (the American Medical Association (AMA) and Canadian Medical Association (CMA)) were able to legitimate their form of medical practice through its association with these scientific advances. At the same time, thay disparaged the practices of other healers as being out-dated and based purely on speculation, rather than on scientifically proven techniques (Conrad schneider. 1981 , 
161).

Larson writes that "once scientific medicine offered sufficient quarantees of its superior effectiveness in dealing with disease, the state willingly contributed to the creation of a monopoly by means of registration and licensing" (1977, 23). In both Canada and the United States, 1 aws and requlations were instituted that favoured scientific medicine and in turn $1 \mathrm{imited}$ other forms of medicine and healing. It was the establishment of this state-sanctioned monopoly over the market for medical services as well as over the recruiting and training of new physicians that allowed the regular practitioners to gain an unparalleled monopoly in the health care arena (Conrad \& Schneider, 1981, 162). It is this control over medical practice that led physicians to achieve dominance over the field of medicine in the twentieth century. Sociologists, intrigued by the special and powerful posjtion held by the medical profession, have developed a field of study that focuses on the role and position of professions in our society.

Naturally, theories and ideas about professions have altered as social and cultural norms have evolved and changed. Medicine has long been considered the prototypic profession and the concept of 'profession' has evolved into an important framework within which to study medicine and its position in our soclety (Hafferty Mckinlay, 1993, 4). In the post World War II period, the literature on the professions, based in 
part on the earlier work of Emile Durkhein, focused on the theme of professional altruism. Scholars arqued that it was the 'service' orientation of professionals that distinquished them from other occupations and allowed them to contribute to the common good of society through their inherent stability and morality (Johnson, 1972, 13). The professions were regarded as a stabilizing force in capitalist society because of their collegial, rather than individualist, emphasis, as well as because of their supposed disregard fur the profit motive (Turner, 1995, 132).

Trait studies of professionalism were also characteristic of this period. These focused essentially on the cataloquing of common characteristics that could be used to describe a general model of a profession. The qoal of this type of work was to define the essential characteristics of a true profession. Although few scholars could agree on all the attributes, the most commonly mentioned traits include specialized skills based on esoteric knowledge, control over the recruitment and training of new members, formal organization, a professional code of conduct and finally altruistic service (Johnson, 1972, 23). This trait approach, however, was limited in its usefulness because it implicitly accepted the professions ' own definitions of their characteristics and roles. It was more descriptive than analytical. It did not provide any critical analysis or theoretical base from which to question the professions and 
their roles and relationships in society.

The failure of these early normative studies to critically examine the nature of power, authority and occupational control in medicine led to the development, largely by the Chicago school of Sociology, of the professional dominance theory. With this work, the ideas of power, process and context were added to analyses of professions and professional roles in society. It is these themes that will inform the analysis in this study.

Navarro writes that "one of the most important theoretical positions put forward to explain the nature of medical knowledge and practice and the organization of medicine has been the professional dominance position, articulated primarily by Eliot Freidson" (Navarro, 1989, 57). Freidson was one of the first scholars to recognize the conflict and complexities in the doctor-patient relationship as well as in the relationship between the medical profession and society. In 1970, he argued that what distinguishes the profession of medicine from other occupations and professions is dominance over the sphere of work. This dominance arises from control over the production and dissemination of knowledge, as well as over the division of labour in medicine, in the provision of health services and in the organization of medical care. Essentially, dominance extends from the monopolistic position that the medical profession achieved throughout the nineteenth and early twentieth centuries. 
Freidson writes that

[i]t is useful to think of a profession as an occupation which has assumed a dominant position in a division of labour, so that it gains control over the determination of the substance of its own work. Unlike most occupations, it is autonomous or self-directing. The occupation sustains this special status by its persuasive profession of the extraordinary trustworthiness of its members (1970, xvii).

In his original works on the topic, Freidson $(1970,1971)$ presented several particular factors that he contended enabled the profession to achieve its dominant position. Essentially, dominance is rooted in autonomy in all aspects of work. And according to Freidson, it is attained through the establishment of educational requirements, licensing procedures and the formation of professional associations. Autonomy, however, is granted by the public and the state in recognition of these attributes as well as in recognition of the collective service orientation of the occupation (Wolinsky, 1988, 36). Therefore, the right to control entry, educational standards, licensire and the production and dissemination of knowledge are all critical in achieving a dominant and thus powerful position in society. Control of medical education, therefore, is an integral factor in establishing and maintaining the dominant position of the medical profession (Blishen, 1991, 5).

Professional dominance and autonomy have several 
important dimensions. Freidson writes that medicine "has the authority to direct and evaluate the work of others without in turn being subject for formal direction and evaluation by them" (quoted in Wolinsky, 1988, 35). Professions will endeavour to gain significant if not complete market control in order to establish a monopoly over the delivery of service. This occurs through the subordination or complete removal of competing providers from the market place. The professional group will also seek to maintain complete control over the delivery of skills and services. Professional dominance also results from the profession's ability to convince the cultural and political elites of the value of its work as well as to gain the public's trust and deference. The medical profession has clearly been able to achieve these latter two characteristics, largely because of the profession's connection to science and glamorous scientific advances. Therefore, Freidson regards professional dominance as control over the profession's own work and that of the other occupations in the division of labour; it also extends to control over patients and the terms, conditions and content of medical work (Coburn, 1992, 500).

Furthermore, a profession will produce and maintain a body of knowledge that requires a significant degree of interpretation, rather than undifferentiated application, in order to be useful. The medical profession's 1 ink to scientific knowledge and technology is essential to its power 
and dominance (Tuohy, 1982, 185-86) and this, in large part, explains the narrowly scientific approach to traditional medical education. The system of educating new doctors, therefore, is integral to the establjshment and maintenance of professional dominance. Freidson writes that "education, therefore, is certainly of great significance, not only for establishing formal criteria for licensing but also for establishing within the individual members of the profession a core of knowledge and attitude" $(1971,88)$.

Control over scientific knowledge allows the profession to maintain its control over the content of medical work. Larson (1977) has argued that perhaps the most important step toward professionalization was "the standardization of the production of the producers" (quoted in Coburn, 1983, 409). Medical education has served to create and to transmit a specific body of knowledge to those individuals who have been deemed acceptable to the profession through the recruitment process.

Johnson (1977, 106) writes that "the professionalism of medicine...is directly related to its monopolization of "official" definitions of illness and health". This monopolization is the result of the control over the body of scientific knowledge that distinguishes physicians from other health care providers. Control over the admissions process also allows the profession to determine who will be allowed, and importantly on what basis, to enter the profession in the 
first place. The standardized and rigid training of medical students that has characterized twentieth century medical education has helped to ensure that all new recruits are socialized into a common model. Larson (1977) asserts that this uniform training creates both the internal cohesion and homogeneity as well as the public credibility necessary for the maintenance of medicine's monopolistic control and prestige in the social order. Professional socialization, therefore, plays a very important role in maintaining professional power.

Freidson's theory of professional dominance provided a framework that allowed for the critical study of professions and their roles. In 1972, Johnson contributed to this focus on professional autonomy and control. He wrote that there are three types of occupational control: collegiate, mediative and patronage (Johnson, 1972, 45-46). Collegiate control is characterized by a relationship in which the producer defines and meets the needs of the consumer. Mediative control occurs when a third party, such as the state, mediates the relationship between producers and consumers. Patronage control exists when the consumer defines her own needs and how they are to be met by the producer. Currently, collegiate control is dominant in the Canadian medical profession. These distinctions, as defined by Johnson, are particulary useful when examining changes in the power and autonomy of the medical profession in light of our changing society and health 
care needs.

Since the first works on professional dominance and control were published, there has been considerable change in both the Canadian and American health care systems. Although Freidson's position has remained largely unchanged (Coburn, 1992, 497), many other scholars have developed theories that address the changing nature of health care delivery and its impact on professional dominance. The two most wel1-known schools of thought on these issues centre their analyses around the ideas of deprofessionalization and proletarianization. Both of these frameworks deal with the apparent decline in the dominance of the medical profession in the face of changes in the health care arena.

Marie Haug first addressed the idea of deprofessionalization in 1973 when she wrote "Deprofessionalization: An Alternative Hypothesis for the Future". She asserts that the medical profession has been gradually losing its dominant position in society because of five key factors. She writes that professions are losing "their monopoly over knowledge, public belief in their service ethos, and expectations of work autonomy and authority over the client" (Haug, 1973, 197). Physicians' "knowledqe monopoly" is being eroded by new technology that allows for automated retrieval of information and symptom assessment. $A$ key component to medizal monopoly and dominance is control over access to training and information and this, arques Haug. 
is being challenged by computer technology.

Physicians are also seeing their authority over patients eroded as general education levels rise and the mystique surrounding science and modern medicine decreases. The growth of consumer self-help and awareness groups has challenged medical control, as has the growth in popularity of 'alternative' therapies and practitioners. Supporters of the deprofessionalization thesis also point toward increasing cost of medical care that has made the medical profession more of a target for questions and criticisms from the public and the state. Increased rates of specialization may also lead to fragmentation and division within the profession that challenges the homogeneity needed to maintain dominance. It is for these reasons that, according to Haug and others, the medical profession is being deprofessionalized. Physicians" dominant position is being gradually eroded by these developments and thus they are in the process of losing their privileged professional status.

The proletarianization argument is based on Marxist assumptions that all workers in a capitalist society will inevitably lose control over their work (Wolinsky, 1988, 39). This argument has called attention to the apparent decline of control and prestige held by the medical profession. Essentially, this theory asserts that professional work is being "deskilled" and "routinized", as shown in the trend toward specialization, just as was the work of skilled 
craftsmen of the nineteenth century (Light \& Levine, 1988, 15). Professionals are coming to depend more and more on the capitalist class for equipment, funding and leqitimacy and therefore their autonomy and control over their own work is being eroded. Without control over the means of production, physicians will increasingly find their autonomy constrained and become employees rather than independent entreprenours.

Mckinlay, a well-known proponent of this thesis, has faulted Freidson for failing to account ror the relationship between the dominance of the medical profession and the capitalist mode of production as well as for the class interests and repercussions of professionalism itself (1988). His work adds the important issues of power and process to analyses of professional roles and work. Mckinlay asserts that the relationship between medicine and capitalism gives rise to the process through which medicine is losing its control over its own position and work. Particularly important are those factors that relate to the context and conditions of work, that have contributed to the profession's dominance (Mckinlay, $1988,3)$.

Unfortunately most of the work published on the medical profession and its apparent decline focus solely on the American situation. The two premises of professional decline discussed above are based on the American experience. Although there are many similarities between the profession in both Canada and the united states, the differences in the two 
systems of health care lead to somewhat different patterns and pressures that must be acknowledged. The Canadian system of health care is currently undergoing a major transformation that will have an impact on the entire division of labour in the health care arena. There are numerous changes affecting our health care system, its organization and the provision of services.

The growth of medicine as a business and the increased involvement of large scale capital interests are regarded as significant threats to the role and position of physicians. The two theories of professional decline, particliarly proletarianization, discussed above are based in large part on the influence of these elements. This threat to physician control and autonomy, however, is much more relevant in the American context with its private health care system. The large American private health insurance companies have considerable control over how the health care system operates and can increasingly dictate the nature of physicians' clinical work. As Tuohy argues, the pattern that has evolved in the United states has served to benefit "the economic discretion of physicians while increasingly constraining their clinical autonomy" (Tuohy, 1993, 20).

In Canada, our public system greatly limits the interests of private capital. Although Canadian doctors are paid by the state, the fee-for-service structure and clinical independence granted physicians allows for the maintenance of considerable 
professional autonomy and control, in comparison to the American situation. The publicly funded system in canada has limited the entrepreneurial discretion of physicians while leaving clinical discretion largely untouched (Tuohy, 1993, 8). The Canadian medical profession's dominance and autonowy are less threatened by the interests of capital than their American counterparts. Currently, increased government involvement, particularly with respect to control of funding, is beginning to challenge professional control over the terms and conditions of medical practice. The government's increased involvement serves, according to Johnson's typology, as third party or mediative intervention that challenges physicians" current collegial control (Blishen, 1991, 142).

Rapid and costly technoloqical change influence considerably the nature of treatment and work. Complex technology is not only costly but also threatens to reduce physicians to the role of technicians, thereby limiting their scope of work and influence. Moreover, increased specialization results from these rapid technological advances. This encourages the decline of professional homogeneity which is, of course, a key factor in professional dominance. In addition, the emergence of a new group of medical administrators, not necessarily physicians, who manage the system in the interests of $f$ iscal control and efficiency. rather than in the interests of the profession, also threatens doctors' autonony. 
The emergence of communal control is evident in Canada today and threatens physicians' dominance in the health care field (Blishen, 1991, 145). The emergence of a more knowledgeable, better educated and questioning public that nu longer implicitly trusts scientific medicine and its practitioners challenges the profession's control over wedlcal care and knowledge (McKinlay, 1988, 2). The growth of selfhelp groups and patients rights organizations indicates the development of a more critical attitude toward physicians and their work. Furthermore, the growing recognition and influence of alternative providers of care, such as midwives, as well as the growth in the autonomy of other occupations within the division of labour, such as nursing, serve to challenge the physicians' monopoly over medical care (Blishen, 1991, 4 ).

A11 of these factors, taken together or separately, serve to challenge and, I would argue, diminish the professional control, autonomy and thus dominance of the medical profession in Canada. The current popularity of medical education reform, therefore, can be assessed in light of the theory of professional dominance and the notions of deprofessionalization or proletarianization. The importance of maintaining control over education as a tool for asserting dominance and maintaining power must be considered when the flurry of current educational reforms are assessed. The reality, both subjective and objective, of the challenges to the medical profession's special position informs the debate 
over curricular reform. Given the threats discussed above, the medical profession is unlikely to engage in change that could further challenge its position. It is also likely to reinforce, through the education process, the connection to acience that has been so integral in establishing the powerful position of the profession. Christakis arques that the current wave of curricular reform is, in part, a response to these threats $(1995,711)$. Education reform is the profession's way of asserting its control over medical education and demonstrating to the public and the state physicians' critical role in the health care arena.

This discussion of professional dominance and power leads to the question of how, specifically, does the system of education, created and governed by the profession itself, perpetuate the structures and characteristics that contribute to the profession's dominant position? The next section of this chapter investigates the process of professicnal socialization as it relates to medical education.

The Sociolery of Medical Education: Professional Socialization

As a discipline, the sociology of medical education was established during the $1950^{\prime} \mathrm{s}$ when reforms were undertaken at the Western Reserve Medical School in response to student dissatisfaction with the structure and environment of the medical program. The changes at Western Reserve mark the 
beginning of the "Social Era" of medical education. During this time, there was widespread concern over the social and emotional needs of the students as well as recognition of the need to incorporate an understanding of social and emotional health into the teaching and practice of medicine. Two clasilc studies of medical students - The student-Physician (Merton et al., 1957) and Boys in White (Becker at a1.. 1961) - sparked interest and debate that lasted for a quarter century into the learning experiences and socialization of students in medical schools. These two early works acted as the catalysts for a whole series of publications on issues relating to medical schools and the process of medical education.

The work undertaken during this period focused largely on sociological and psychological issues. The study of medical education as a social phenomenon restricted the field of study to concern over issues such as: "the fate of ldealism, the development of a professional self-image, training for uncertainty and detached concern, coping with too much work and handling mistakes" (Light, 1988, 312). Much of the work of the 1960's, 1970's and even early 1980's, therefore, has contributed to our understanding of how students are socialized into their professional roles throughout their years of training, undergraduate and post-graduate included. As mentioned previously, soclological research on the professions during the $1950^{\circ} \mathrm{s}$ and $1960^{\circ} \mathrm{s}$ focussed on developing definitions and lists of traits that could 
characterize the professions. This position logically led to an interest in how the characteristic traits were acquired by members of the profession. This focus, therefore, informed the studies of the socialization of new trainees in professional schools. Merton, Reader and Kendall's student-Physician presented a series of studies based on the theme that

it is [the schools'] function to transmit the culture of medicine and to advance that culture. It is their task to shape the novice into the effective practitioner of medicine... to provide him with a professional identity so that he comes to think, act and feel like a physician. It is their problem to enable the medical man to live up to the expectations of the professional role long after he has left the sustaining value-environment provided by the medical school (1957, 7).

For Merton et al.. the medical school is an institution within the profession. It acts to initiate new recruits into the group and convey to them the shared ideas, values and behaviours expected by members of the professional group. The authors argued that the acquisition of a set of distinctive roles, values and traits was a key goal of the education process and their work examined how these attributes were transmitted to the students. students were presented as 'junior colleagues', rather than students, being groomed and guided by their more senior colleagues toward full professional status. The study examined various factors and situations that contributed to the socjalization process that occurred during the years of medical training and established 
the importance of considering the medical school as a learning environment (Bloom, 1979, 9). Essentially a functionalist interpretation of socialization, there was no critical analysis of the status of the profession and the roles being taught to the 'student physicians'.

Becker, Geer, Hughes and strauss of the Chicago School of Sociology presented an alternative to the student-physician with the publication of Boys in white, a study of students at the Kansas Medical School. This important study stressed the immediate experience of the students and their coping strategies, rather than the relationship between current socialization and the future practice of medicine as discussed in the student-physician. The authors concentrated on how the students coped with their immediate situations, with a specific interest in the notion of 'student-culture' and how it shapes the experience for all students. Little emphasis was placed on making connections between the students immediate experiences in medical school and how these influenced their attitudes and behaviour as physicians. Unlike Merton et al., the medical school was understood more as an independent institution rather than part of the larger structure of the medical profession.

These two works shaped the nature of debate and study of medical education for years afterward. In 1988, Light wrote that these studies "may have provided rich insights... . but in retrospect it seems remarkable that so many of us spent twenty 
they wear, from the very beginning, the white "lab" coat that immediately identifies them as members of the medical profession. They are introduced to patients as "young doctors" or "student doctors on the medical team" (Conrad, 1988, 327) and thus carry with them, from the outset, the elevated status that belongs to the profession. The early identification with the profession of medicine encourages the unity and homogeneity r.hat helps perpetuate the profession's dominance. with this new identity, however, comes the expectation that they will adopt :he characteristics and attitudes belonging to this professional identity (Conrad, 1988, 327). Medical students are forced early on to adopt the language and terminology of medicine. The ability to use this scientific language helps incorporate the students into the profession while at the same time distinguishing them from the public. A student in McMaster's program notes that

[p]eople in medicine have a world unto themselves and a language unto themselves. It's a world with a vocabulary... and a vocabulary that, no question about it, creates a fraternity that excludes the rest of the world and it's a real tyranny to lay people who don't understand it... (haas o shaffir, 1978, 77).

In their goal of becoming 'competent' physicians, medical students' attitudes toward their patients change over the course of their training. As students struggle with often excessive responsibility, overwork, sleep deprivation and an overwhelming base of knowledge to learn, their ability to cope 
the learning of social roles and occurs largely through social interaction with superiors, peers, other health care workers and patients. Bucher and stelling conclude that medical training programs are "...highly successful in molding and shaping the trainees' emerging sense of profossional identity and commitment and the way they [come] to define their own professional roles" $(1979,140)$.

Professional training, therefore, entails more than learning technical knowledge and skill. It provides an introduction to the culture and ethic of the profession and it encourages the students to develop a virtually unquestioned commitment to an 'appropriate' professional career (Chappell \& Colwill, 1981, 68). It also serves to teach students a particular notion of what defines and constitutes health and illness. Structural interactionists Haas and Shaffir argue that students adopt a professional image as they undergo the training process; they develop a new view of themselves as they become part of a new culture with its own self-image, status and role (Haas \& Shaffir, 1978, 72). In sum

[m]edical students learn a new symbol system that not only distinguishes them as neophyte members of a distinctive powerful community but it creates an imagery of authoritativeness and competence (Haas \& Shaffir, 1978, 86)

Jamous and Peloille (1970) describe the function of the medical school in terms of the transmission of two types of knowledge or training that they termed 'technicality and 
indeterminacy'. Technicality refers to the technical skills, procedures and knowledge that are required to undertake the day to day work of a physician. Indeterminacy, on the other hand, refers to knowledge that is transmitted through example and observation and is reflected in the attitudes, values and behaviour of the practising physician (Chappell a colwill, 1981, 68). The medical school, therefore, has a dual function that is reflected in the existence of both manifest and hidden curricula.

Professional socialization results in large part from the interaction of structural and situational aspects of the training program. It is the nature of the training program itself and the experiences of the students, as well as the courses and content being taught, that impacts on the attitudes and views of the students (Bucher o stelling, 1977, 257). The impact of role playing and role models on the process of professionalization of medical students is critical. It is mainly through role playing activities that students gain their

...sense of mastery, their definitions of
what constitutes the really interesting
and important work of the profession, and
their perceptions of their own future
professional roles... [T]he professional
characteristics and preferences of
graduating trainees are patterned by what
they do on a day-to-day basis as they
move though their training program
(Bucher \& stelling, 1979, 149).

Medical students are taught clinical skills in an apprenticeship type program where often the dominant approach 
to teaching is 'see one, do one, teach one' (Conrad, 1988, 326). Therefore, they learn the practice of medicine by observing the work of the physicians assigned to teach them and will model their own practices, beliefs and behaviours after those of the physicians that they observe. It is assumed that students will learn better clinical skills by watching and doing than by studying. But while students successfully learn these clinical skills, they are also absorbing the culture, philosophy and practice patterns of the profession. Klass, a physician, writes that

[ $t$ ] he experience of being socialized into a medical student class was at times disturbing, as was the sense that we were being taught values, though not explicitly, along with basic science and pathophysiology $(1987,29)$.

In this way, the profession can replicate itself with each class of new physicians. Moreover, as students watch, imitate and practice these skills and attitudes, they increasingly identify with the organization and practices of the profession (Haas Shaffir, 1978, 76). As a result, students are absorbed into the profession and accept more willingly its dominant ethos.

This process of professionalization is facilitated by the symbols adopted by the profession that set them apart, or indeed, above other health care practitioners and the public. Medical students, although at the very bottom of the medical hierarchy, are included as part of the health care team from the outset of their training. They acquire a new identity as 
they wear, from the very beginning, the white "lab" coat that immediately identifies them as members of the medical profession. They are introduced to patients as "young doctors" or "student doctors on the medical team" (Conrad, 1988, 327) and thus carry with them, from the outset, the elevated status that belongs to the profession. The early identification with the profession of medicine encourages the unity and homogeneity rhat helps perpetuate the profession's dominance. with this new identity, however, comes the expectation that they will adopt :he characteristics and attitudes belonging to this professional identity (Conrad, 1988, 327). Medical students are forced early on to adopt the language and terminology of medicine. The ability to use this scientific language helps incorporate the students into the profession while at the same time distinguishing them from the public. A student in McMaster's program notes that

[p]eople in medicine have a world unto themselves and a language unto themselves. It's a world with a vocabulary... and a vocabulary that, no question about it, creates a fraternity that excludes the rest of the world and it's a real tyranny to lay people who don't understand it... (Haas shaffir, 1978, 77).

In their goal of becoming 'competent' physicians, medical students' attitudes toward their patients change over the course of their training. As students struggle with often excessive responsibility, overwork, sleep deprivation and an overwhelming base of knowledge to learn, their ability to cope 
with the emotional demands of the work is compromised. A major effect of medical education, therefore, is the loss of a caring attitude (Moore-West at al., 1990, 128). This is often explained as the replacement of 'idealism' with 'realism', according to the medical profession, or 'cynicism', according to the sociologists. Medical training is set up so that the provision of care is discouraged. Virtually all clinical teaching focuses on diagnosis, treatment and intervention of disease. So the technical and scientific sides of medicine, those that contribute most to the profession's powerful and dominant position, are stressed at the expense of quality care and compassion. Students gradually accept the notion that maintaining clinical objectivity, a key criterion for 'competence', calls for the objectification of the patient. Moreover, because of their busy and stressful schedules, students believe that they simply do not have time for both learning and caring (Haas Shaffir, 1978, 79).

Even as early as their first year, students are learning to shut out their emotions and depersonalize their work. The experiences in the first year Gross Anatomy laboratories where students dissect cadavers has long been accepted as the students ' initiation into the profession (Conrad, 1988, 325). In this laboratory, students often experience death for the first time and undertake procedures far removed from anything ever previously undertaken, such as cutting open a human body and removing the internal organs. Any sort of emotional 
reaction to the experience is strongly discouraged and students learn to objectify their cadavers, and in turn the human body, in order to deal with the experience. The whole exercise is viewed as a chance for students to prove to themselves and others that they have what it takes to become a doctor (Hafferty, 1991, 53). Klass writes, with respect to her experiences in anatomy lab, that "for the first time in medical school, I have the sense that I an being initiated into a priesthood. This is something normal people never do" $(1987,37)$.

In his book Into the Valley: Death and the Socialization of Medical students, Hafferty writes that students ...having successfully weathered $l a b$ as a rite of passage, have come to internalize the norm that they must occasionally and defensively view some of the objects of their work as less than like-me and other than fully human ... They learn that the category 'human' is neither unidimensional nor static and that it is perfectly permissible and even necessary ...to attach the prefix 'more' or 'less' to the root word $(1991,207-208)$.

This process of socialization contributes to the dominant position of the medical profession in our society. Medical training helps mold the profession's new recruits into a homogenous group possessing the beliefs, attitudes and knowledge that serve to perpetuate the power and authority wielded by the profession. Socialization into the profession of medicine, therefore,

... involves the adoption and manipulation of symbols and symbolic behaviour to 


create an imagery of competence and
separation and elevation of the
profession from those they serve (Haas
Shaffir, 1978,73$)$.

The education system, its content, structure and socialization process from admissions to post-graduate work, contributes significantly to the achievement and maintenance of professional dominance. Currently, both the manifest and hidden curricula in medical schools are key elements that help perpetuate the structure, philosophy and culture of the profession as it has evolved this century. Historically, the medical profession gained its powerful role in society through the establishment of a state-sanctioned monopoly over medical care and education that was based, in large part, on the profession's position as an intermediary between the public and the advances of modern science. The following chapter will investigate this theme in the context of the history of North American medical education. 
Chapter Three

\section{A HISTORY OF MEDICAL EDUCATION}

In 1910, Abraham Flexner and the Carneqie roundation published a report that assessed the state and quality of medical education across the United states and canada. The report, Medical Education in the United states and Canada, is the best known study of North American education published this century. In the seventy-five years since Abraham flexner and the Carnegie Foundation launched their scathing attack on the state of medical education in canada and the United States, there has been an on-going debate over the need for undergraduate medical education reform. In fact, perhaps the most important theme in the history of medical education in both countries is that of continual dialogue over the qoals of medical education and in turn debate over how to achieve these goals. The purpose of this chapter, then, is to outline the history of medic:l education and attempts at its reform in order to develop a Iontext within which current practices and reforms can be examined. Both the Canadian and American experiences will be explored because of the similarities in medical training and practice that existed at the time.

Twenty years after Flexner published his famous report, the Commission on Medical Education of the Association of American Medical Colleges released, in 1932, a study that was very critical of medical education as it had evolved in the 
early part of the twentieth century. The commission believed, as did Flexner, that medical schools were teaching too many subjects in too much detail, that dependence on sheer memory and didactic teaching were limiting the learning potential of the students and finally that medical curricula had become too rigid.

Fifty two years later in 1984, The Report of the Project Panel on the General Professional Education of the Physician (GPEP Report) repeated many of the same concerns that both Flexner and the 1932 Commission had raised and acknowledged. In spite of repeated calls for change, very little had in fact been done to reform medical education in the intervening years. The GPEP Report states that

[a] review of past efforts to modify medical education reveals that most of the problems identified in the course of this project are not new. Institutions intermittently have changed their curricula, but unfortunately little progress has been made toward a fundamental re-appraisal of how physicians are educated (GPEP Report, 1984, 8)

Medical educators assert that physicians who will practice medicine in the twenty-first century cannot be prepared adequately by the system and the ideology of medical education that originated in the nineteenth century. The history of medical education reform is clearly a history of dialogue without change. While there has been widespread recognition of shortcomings in the content and approaches to the structure of medical education established at the turn of 
the century, attempts at addressing these problems have been sporadic, limited and not surprisingly, have had little, longterm impact on the educational experiences of medical students. Study of the history of medical education demonstrates that the current reform debate is neither new nor particularly innovative.

Changes that have been advocated for the past sixty five years have failed to be incorporated successfully into the mainstream of medical education. One of the best known and longest lasting changes instituted, the organ based curriculum at Case western Reserve in the 1950 's, is still referred to as an 'experiment' in medical education (Bussigel, Barzansky and Grenholm, 1988, 1). The few schools that have instituted alternative curricula are still regarded dubiously by the traditional schools. They must continually prove their worth by showing that their students can succeed on the often criticized, profession-wide licensing examinations that reflect traditional education practices. The current themes and curricular developments in the field of medical education are so similar to those of past years that present reform initiatives can be understood as extensions of a constant dialogue about change that has had little impact on the reality of the process of educating physicians. 
Nineteenth Century Medical Education

During the nineteenth century, the dominant force in both Canadian and American medical education was the proprietary medical school. In general terms, proprietary medical schools were privately-run, profit-seeking institutions that were not part of established universities. In Canada, such schools were governed and regulated by the medical profession. In the United States, however, they were not regulated in any way and as a result 'free enterprise' in medical education characterized tl.e times. In the United States, the lack of minimal curricular and licensing requirements meant that there was a tremendous variation in the quality of physicians graduated (Starr, 1982, 113). Any group of practising physicians could come together and charge tuition fees to any student that they wished to instruct.

Although many of these schools graduated educated and skilled physicians, others were less successful. Kaufman (1976, 44) asserts that the quality of education that these institutions offered varied considerably, but that many provided an inadequate education, of ten with poor lectures, no clinical experience and no access to libraries or laboratories. Medical education reformer Charles Eliot wrote in 1870 , that

[ $t$ ] he ignorance and general incompetency of the average graduate of American Medical Schools, at the time he receives the degree which turns him loose upon the 
community is something horrible to contemplate (quoted in Starr, 1982, 113).

During this period, the AMA, founded in $184 \%$, and slight]y later the Association of American Medical Colleges (AAMC), founded in 1876, were created, in part, to respond to concerns over the quality of education at some of these proprietary schools. In the $1850^{\prime}$ 's, the AMA developed a set of minimum standards for pre-medical and medical education, but the lack of enforceable licensing statutes and medical laws limited the effectiveness of the AMA actions. In fact, in 1869, the AMA executive requested, with little success, government assistance in the form of federal legislation to raise the standards of medical education in the United States (Jonas, 1978, 191). The desire to "raise standards" and limit numbers not only reflected concern over the quality of physicians. It was also based on the desire to establish scientific medicine as the only legitimate healing profession in North America, thus having a positive impact on the prestige, wealth and power of the profession as a whole. This goal led them to organize themselves into a more homogenous and structured body and to seek control over the process of screening and educating all aspiring physicians. The profession used its connection to science and scientific advances to gain the trust and confidence that enabled them to establish, with state support, a monopoly over medical care. Their success in this regard reflects their wealth and position in society as well as the legitimacy of their claims 
of scientific superiority. These, in turn, allowed the physicians to achieve a dominant position in society.

As Gidney and Millar (1994, 53) argue, in spite of the many similaritics in both medical practice and training, the history of medical education in nineteenth-century Canada is not simply a reproduction of the American experience on a smaller scale. Although there was a continual struggle between regular and irregular healers (Blishen, 1991, 9), the profession in Canada was more successful at an earlier date in achieving its dominant position. The establishment of powerful licensing and examining boards whose mandates were, in part, to determine standards of medical education distinguished the Canadian experience from that of the Americans. In Upper Canada, for example, the legislature passed the ontario Medical Acts of 1865 and 1869 that created the General Council of Medical Education and Registration. The 1865 Act gave the profession considerable control over the education and licensing of medical doctors. It took control of medical education from individual institutions and placed it firmly with the newly created College of Physicians and Surgeons of Upper Canada. In Lower Canada, The College of Physicians and Surgeons was established and given control over stindards of entry and training in 1847 (B1ishen, 1991, 10).

During this period, however, most Canadian medical schools, like their American counterparts, were only tenuously if at all connected to established universities. Most medical 
schools were privately run, proprietary institutions that were affiliated with universities only to the extent that their students received their degrees in the name of the affiliated university. The first medical school in Canada was established in Montreal in 1824. Initially, it was a proprietary school but it soon became affiliated with McGill University. stronger and better enforced standards and regulations as we 11 as a more organized and centrally controlled professional body, however, ensured that the very poor quality education offered at some American institutions was not to be found in Canada.

In order to limit the growth of small, private medical schools and centralize medical education in larger centres with extensive hospital facilities, the Medical Councils of Upper and Lower Canada specified that no recognition would be given to training received at an institution where "any lecturer...lectures on more than one branch of medical science; nor...delivers more than one lecture daily" (quoted in Gidney and Millar, 1994, 54). Both higher and standardized entrance requirements were instituted in order to restrict entry into the profession and to gain the prestige and public recognition that the profession sought during this period. Finally, the governing bodies of the profession established the successful completion of two universal examinations as a prerequisite to 1 icensure. Several specified courses and clinical experiences were required in order to write these 
exams.

As a result of these requirements, Canadian proprietary schools were more successful in incorporating new scientific and clinical approaches into their programs and as a result were recognized as high quality institutions both at home and internationally (Gidney and Millar, 1994, 53). The creation of such centralized bodies of control served to mitigate some of the excesses of the American experience that gave pre-Flexner, proprietary medical education its poor reputation. These measures helped to standardize medical curricula in Canada and ensured that all new physicians met a common minimum level of competency.

These measures differentiate somewhat the evolution of medical education in Canada during the second part of the nineteenth century from the trends that were evolving in the United states at the same time. In later years, proprietary education would come to be associated with an out-dated and poor quality system of education because of the American experience. In spite of the Canadian schools' consistently higher standards, concern over the quality of medical education in Canada was widespread. Many of the themes advanced by American educators, particularly with respect to curricula and pedagogy, were echoed by their canadian counterparts. As in the United States, calls were made for more clinical instruction, less didactic teaching and more small group learning, more laboratory work and less "book 
work" (Gidney and Millar, 1994, 56).

The leading professional bodies in both countries sought to standardize the process of educating new physicians. The profession clearly saw standardizing medical education, with a scientific orientation, as a tool to establish a dominant position among all health care practitioners as well as to gain credibility, public support and respect for their profession. These licensing laws were instituted to 1 imit access to the profession to a select few students based on class, race and gender and to set physicians apart, indeed above, all others who provided health care services, such as homeopaths and midwives (Mitchinson, 1991, 22). The medical profession's dominant position in the twentieth century has its roots in the actions and events of the nineteenth century. The education process with its strong connection to the advances of scientific knowledge and skill was clearly used to help establish and maintain the powerful position enjoyed today by medical doctors.

\section{Abraham Flexner and Twentieth Century Medical Education}

The renowned Flexner Report, pubilished under the title Medical Education in the United states and Canada, was commissioned by the Carnegle Foundation and released to the public, with considerable coverage by the popular press, in 1910. Abraham Flexner is generally credited as the founder of 
contemporary North American medical education. Further study of the issue reveals, however, that, as he publicly acknowledged himself, his work in large part solidified, rather than initiated, a trend that emerged from the establishment of Johns Hopkins medical school twenty years prior. As historian R. P. Hudson makes clear, "Flexner's contribution was not so much revolutionary as catalytic to an already evolving process" (1992, 13). Moreover, much of his work and contribution to medical education has been misrepresented.

The Hopkins approach that was so influential in the evolution of twentieth century medical education was based in large part on scientific approaches learned from the German system of medical training (Huddle, 1993, 551). In Germany, medicine was taught as a laboratory-based science in a university setting. William osler, one of the founders of Johns Hopkins and a graduate of the McGill medical school in Montreal, wrote that

[ $t$ ] he characteristic which stands out in bold relief in Gernan scientific 1 ife is the paramount importance of knowledge for its own sake... The presence in every medical centre of a class of men devoted to scientific work gives a totally different aspect to professional aspirations... (quoted in Huddle, 1993, 552 ).

Juhns Hopkins was one of the first privately endowed medical schools in the United states and thus it could operate largely independently of student income. It was also 
integrated into the university itself. Based on the German influence, the lock step approach to medical education of two years of basic sciences and two years of clinical work and the emphasis on basic science research still seen today was established initially at Johns Hopkins. It was also emulated by several institutions, including Harvard, in the years prior to the publication of Flexner's report (Hendrie 1.loyd, 1990, 130). In fact, the Hopkins system became the model for twentieth century medical education and thus the medical school as it exists today.

In 1905, the AMA's Council on Medical Education developed another set of minimum standards, that it termed an "ideal standard". It included two years of university level basic science, two years of laboratory work in medical school with a focus on anatomy, physiology and pathology, and two years of supervised clinical work. This standard, clearly based on the Hopkins approach, served as the basis for some of Flexner's recommendations five years later and it is evident today at traditional medical schools in both canada and the United States.

Although Flexner's conclusions and suggestions were not particularly original, his work was still an important contribution to the establishment of our present system of medical education. It initiated debate over medical education and certain parts of the document helped strongly reinforce the already emerging pattern that has come to characterize 
twentieth century medical education. The medical school format, however, that has come to be known as "Flexnerian" bears only partial resemblance to what flexner actually recommended in his report. Unfortunately, many of his recommendations were ignored, to the detriment of twentieth century medical education.

His work was, at that time, the most comprehensive study of North American medical education and it continues to be the most scathing and blunt of all such reports. It contained, for all to read, specific names and places of institutions with what he considered disgraceful conditions. Flexner visited every medical school in the United States and canada, for a very short time each, and rated them according to the criteria that he deemed important for good quality medical education. He looked at entrance requirements, staffing, financial resources and laboratory and clinical facilities. Clearly, he believed that good facilities, high entrance requirements and considerable financial support produced quality education. Flexner concluded that the conditions and quality of North American medical education were disgraceful. of the eight Canadian medical schools that existed at the time, he found only the MCGill and the University of Toronto schools comparable to the better American schools. He was most critical, however, of the Halifax Medical College and the Western University Medical Department largely because of poor laboratory and clinical facilities (Flexner, 1910, 321-322). 
Flexner believed that the scientific method used in the basic medical sciences, taught through laboratory instruction not didactic lecture format, was the best foundation for both medical research and medical practice. He was very critical of the extensive use of lectures and didactic teaching methods, coupled with an examination system that required and rewarded rote memorization. He believed that clinical teaching should take place through clinical clerkships in well-equipped and 'modern' dispensaries and hospitals. In his mind only wellfinanced, university-based medical schools could provide such conditions (Flexner, 1910, 53-60, 96-100). His best known recommendations called for a minimum of two years of undergraduate pre-medical university work, two years basic science and two years of clinical training with laboratory work emphasized. He also recommended that medical schools be incorporated into university structures so that medical teaching could be closely linked to scientific medical research. These recommendations, however, only reinforced the pattern of education already endorsed by the council on Medical Education (CME) and the profession's governing bodies. Flexner has been credited, or criticized, for the establishment of the "lock-step, two-plus-two basic scienceclinical curriculum", the widespread acceptance of a narrowly scientific two-year period pre-medical training and the concentration of faculty on scientific research at the expense of teaching. These characteristics are closely associated with 
medical education in the twentieth century (Bonner, 1990,9). The narrowly scientific focus of medical training that stemmed from these characteristics has been generally linked to his report. Yet, in reading his report, it becomes clear that his intent was never to create the rigid and standardized curriculum that has been credited to his work. He included many recommendations that have largely been ignored, to the detriment of the evolution of twentieth century medical education. His writing demonstrated an understanding of the social role of physicians, the value of preventive medicine, the importance of good teaching in medical school and the necessity of humanism in medicine (Bonner, 1990, 9).

At the beginning of his report, Flexner wrote about the importance of preventive health activities to the well-being of society, the social responsibility of medical schools and physicians, the inappropriateness of profit in both medical practice and education, as well as the importance of state regulation in preserving the interests of the public. These recommendations were ignored in the development of medical schools during the early part of this century. The failure to consider these factors led directly to the curricula that is widely criticized today. In fact, only three years after the publication of his Report, Flexner wrote that "the American medical school closes down upon the enterprising student with an exhausting and depressing uniformity" (Flexner quoted in Bonner, 1990, 8). A decade later, he wrote that "students move 
through medical school in tight lock step, and have little time to stop, read, work or think... anything more aljen to the spirit of scientific or modern medicine...can hardly be contrived" (Flexner, 1925, 149). Historian Edmund Pelliqrino has arqued that it was not Flexner "who led us into the desert of narrow, fact-packed, anti-humanistic medical curricula", but rather the unimaginative leaders of American medicine who misinterpreted the core of Flexner's report and also sought to modify medical education, through a narrowly scientif ic focus, not only to improve its quality but also to use it to better their own professional interests (Pellegrino, 1987, 106).

Flexner, in spite of some of his progressive recommendations, has been referred to as a "prize academic snob" by historians (quoted in Bonner, 1990, 6) for providing the medical profession with reforms that consolidated their power and control over the entire health care arena. The reforms to medical education of this time reached well beyond the simple restructuring of the medical schools in order to better the quality of education. The impetus for the rapid acceptance of reforms attributed to Flexner had as much to do with politics as with pedagogy.

Flexner's reforms helped to promote physicians' pursuit of professional dominance in the health care field. Controlled entry and standardized education governed by the professional group, self-regulation, community trust and respect as well as internal unity are key elements to professional control and 
autonomy, as was discussed in chapter two (Freidson, 1970). The proprietary schools that were so strongly condemned by Flexner provided medical education largely to students who did not have access to university-based training, for reasons of geography or class (Hendrie Lloyd, 1990, 1:1). In the introduction to The Flexner Report, Henry Pritchett, President of the Carnegie Foundation wrote

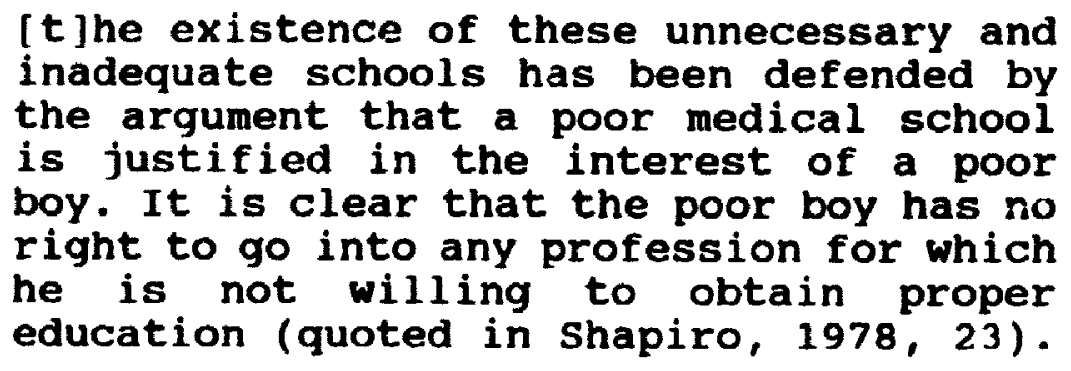

It was in the interest of the developing medical profession to limit the number, and thus type, of students entering the profession as well as to standardize the nature of the training that the 'suitable' students received.

At the time, there was a widespread perception that the profession was being flooded with new graduates. Flexner complained that the nineteenth century had been "a century of reckless overproduction of cheap doctors" (quoted in Ebert, 1975, 112). This perceived overproduction was seen as a threat to the power, cohesion and wealth that the profession's leaders, particularly those involved with the AMA, sought. Small, proprietary schools had allowed those who were barred, for reasons of race, gender and class, from studying at the well-known and well-endowed institutions, the opportunity to become physicians. During the course of the nineteenth 
century, over 400 medical schools opened their doors in canada and the United states but by the time Flexner published his report in 1910, only 160 remained (Ebert, 1975, 112). In his report, Flexner proposed that the number of medical schools be reduced from the 160 that were operating at the time to only 31. The higher entrance requirements, longer periods of study and higher tuition clearly served to limit accessibility to the profession. As a result of the changes following The Flexner Report, the per capita ratio of physicians in the United States declined cor: iderably between the years of 1900 and 1930 from 173 per 100,000 to 127 per 100,000 (Rothstein, 1987, 120). Five of the seven medical schools that educated black Americans closed in this period and the number of women declined and was then limited, by quota, to five percent of admissions (Starr, 1982, 124).

These changes served to establish medicine as an occupation for the elite, at the same time as they encouraged cohesion and a unified commitment to the principles of the profession. As Berliner (1975, 575) has arqued, physician support of The Flexner Report was based in part on the desire to eliminate competing medical groups and to further establish medical doctors as the only legitimate healers in American society. Following The Flexner Report, medical education became standardized in its admissions and course requirements and the AMA introduced requirements for 1 icensing of American medical schools. 
clearly, what differentiated allopathic medicine from other health care providers was its close connection to science. It is the emphasis on science that helped provide the profession with the prestige and public support it needed to become the dominant force in the health care delivery system. In addition, close ties to universities and a strong commitment to the newly developing sciences served to raise the status and prestige of the profession. The leaders of the profession and the medical educators were selective in their implementation of Flexner's recommendations. Those that served to benefit the status of the profession were chosen for implementation, while others were ignored. The two-plus-two curriculum, the upgraded admissions standards, the emphasis on basic sciences and university affiliation were certainly in Flexner's Report, but were not representative of the whole of his vision for medical education.

As Coburn et al. (1983) note, however, the Flexnerinspired reforms did not have as significant an impact in Canada as they did in the United States, particularly in terms of school closure and reducing accessibility to the medical profession. By this period in Canada, physicians had already been more successful in establishing control over education, licensing and the structure of the health care field and thus accessibility to the profession had already been significantly limited and controlled. The Canadian medical profession was more successful at an earlier stage, in large part because of 
state co-operation and the smaller number of practitioners, than their American counterparts in establishing themselves as a powerful, homogeneous and well-respected group.

In 1912, the Canada Medical Act was passed. This piece of legislation sought to standardize the licensing of medical practice across the entire country and further strengthened "the autonomy and collegial control of the profession and its ascendancy over other occupations in the health field" (Blishen, 1991, 18). Canadian medical schools did, however, change their curricula according to some of Flexner's proposals and this strongly reinforced the already existent trend toward professional dominance. Medical education in Canada became firmly established within the universities and the process of education became more standardized across the continent. Like their American counterparts, Canadian medical educators ignored the more progressive, socially aware recommendations and focused their efforts on reinforcing the primacy of science in medical training. The link between medical education reform and professional aspirations was thus clearly established at this time and has continued to influence the nature and substance of debate to the present day.

The Peried of consolidation

The drive to standardize medical education remained 
entrenched in both the United states and Canada well into the 1950's. Medical school structure, curricula and admissions policies across both countries were virtually identical. The first two years were devoted solely to basic sciences and the last two to clinical medicine. The first year included traditional courses in anatomy, physiology, biochemistry; the second always included courses in pathology and pharmacology. The third and fourth years would usually be spent doing clinical work in general medicine and the specialties. In most schools the curriculum was entirely structured; there was no personal study time included and rarely any electives allowed (Rothstein, 1987, 153). There was little if any time devoted to the study of social and environmental aspects of health and disease. Study of the social sciences and public health was almost entirely disregarded. The fate of a thirty-three hour course in medical sociology offered at the Indiana University School of Medicine in 1912, is instructive. The course was first 1 isted in the Department of Internal Medicine but after several years, the course was transferred to the Department of Social Work and reduced in length. By 1930, the course had been abandoned altogether (Hendrie \& Lloyd, 1990, 76). In the $1930^{\prime}$, only 18 of the 100 American medical schools had departments of public health (Rothstein, 1987, 154).

In sum, in the years following Flexner, most schools concentrated increasingly on the scientific aspects of disease, while spending little time, if any, on the social, 
psychological and environmental factors that influence both individual and community health. The closure of most of the small medical schools in small communities further concentrated medical education and thus medical services in urban areas.

As early as 1925, both Flexner and the AAMC itself were beginning to recognize some of the shortcomings of the system of medical education being established and consolidated.

Various efforts... have largely eliminated
the proprietary and commercial schocls
and have established certain minimum
requirements which are regarded as
necessary for proper training. These
regulations...have led to great rigidity
and a considerable amount of over-
regulation... The medical faculties...have
created great overcrowding of the
curriculum... There is now need for a
sounder basis of action on the part of
the regulatory bodies and the various
organizations concerned with both general
and medical education in formulating
requirements for licensure and training
(AAMC, 1925 . l65).

Flexner expressed concern that the desire to "stamp out" socalled unfit medical schools had led to undesirable regimentation, over-specification and specialization. Unfortunately, his concerns and those of the AAMC were not widely acknowledged. Ef forts at counteracting the trend toward a narrow, regimented, biomedically focused education were not undertaken and this pattern of medical education persists to this day (Bussigel, Barzansky and Grenholm, 1988, 21).

The changes initiated during the beginning of the 1900's, encouraged by The Flexner Report, had largely been 
consolidated by the late 1920's. In 1932, the AAMC's Commission on Medical Education published its well-known $F$ inal Report on Medical Education. Interestingly, many of the observations and recommendations made in this study are still relevant today and can be clearly seen in the 1984 GPEP Report. Although the Commission was concerned with what it saw as government interference and an oversupply of physicians, it stressed, like The Flexner Report, the importance of preventive care and medicine as a social institution. With respect to education, the report called for increased flexibility, less emphasis on lectures, memorization and examinations and more integrated clinical training (Jonas, 1978, 238). The publication of this report led leaders in the medical community to recognize the shortcomings of the 'Flexnerian' system of education, although the Depression and the Second World War focussed attention on other aspects of medical training.

Innovations in Medical Education: The 'Social' Era of Reform

The 'social' era of medical school reform originated during the 1950's and continued through the 1960's and early 1970 's. During this period virtually every North American medical school made at least minor changes to the structure of its curriculum. The 'social' era was characterized by expansion and experimentation in approaches to medical 
education (Hunt, 1991, 52). The social and ethical aspects of medicine were increasingly recognized and occasionally incorporated into medical teaching. In 1952, the western Reserve University School of Medicine undertook considerable reform of its educational environment and its curriculum. This development marks the beginning of the social era in medical school reform and indeed most of the changes subsequently made at other medical schools were based on those first undertaken at Western Reserve (Hunt, 1991, 53).

The school's new philosophy and structure were based, in large part, on the concern that the traditional curriculum did not foster a "humane educational environment for the students" (Moore-West et al, 1990, 129). Also, there was concern over the traditional science-based model of curriculum that had become so firmly entrenched in the first half of this century. The medical school moved to an organ-systems based curriculum. Instead of a discipline-based approach, content was organized around body systems. For example, rather than taking specif ic courses in anatomy, biochemistry and pathology, students studied the respiratory system or circulatory system from all aspects. This method of learning integrated basic science teaching across disciplines and increased the relevance of the basic sciences to clinical medicine. Interestingly, this reform is one of the main initiatives currently being implemented at Canadian medical schools. The re-structured Western Reserve curriculum also recognized that an 
understanding of the behavioral sciences as well as social and ethical issues were important to the study and practice of medicine. In addition, student participation in the educational process as weil as more active student learning formed the basis of the school's new approach to learning.

Western Reserve's new curriculum and the subsequent revisions that were undertaken have never been subjected to rigorous evaluation and thus it is not possible to ascertain conclusively whether the changes undertaken made a difference in how graduates practiced medicine and treated their patients. In his 1980 study of the Western Reserve initiative, Western Reserve's Experiment in Medical Education and Its Outcome, williams writes that data and evidence in regards to the impact on the practice patterns of graduates of Western Reserve's modified curriculum "is inconclusive or totally lacking because of the impossibility of controlling a host of independent variables" (457). Regaraless, williams tentatively asserts that the students who have studied under Western Reserve's new program, unlike students at most traditional schools, found their experience rewarding and felt that their time in medical school was well-spent. Western Reserve's students maintained similar success rates on the licensing exams before and after the curriculum was altered. This demonstrates, perhaps, that these new approaches to teaching did not adversely affect the students' acquisition of knowledge and skills, although it might also suggest that 
little had changed in terms of the basics of scientific medical training.

The Western Reserve experience was also valuable because it launched a period of widespread assessment and study of the merits of the traditional undergraduate medical curriculum. As Williams writes, "cleveland became a medical tourist attraction" (1980, 456). The Western Reserve experiment served as the catalyst for the widespread, but unfortunately of ten ineffectual, curricular changes undertaken by other institutions in the 1960's and 1970's. Many schools opted for a compromise that provided for traditional disciplinary teaching during the first year followed by an integrated, interdisciplinary systems-based second and third years (Lippard, 1974, 18). Williams concludes that the experiment at Western Reserve may have been successful, particularly in the early period before changes were made that brought the curriculum back to the more traditional structure. However, the success was not due primarily to the content of the revised curriculum itself but rather to the attention that the experiment brought to the need for curricular reform.

Bussigel et al $(1988,23)$ assert that in the $1960^{\prime} \mathrm{s}$ and 1970's the dominant forces affecting medical education, in both Canada and the United states, were the desire to increase the number of physicians and to improve access to medical services, the tremendous growth in funding opportunities for biomedical research and a growing discontent with the strictly 
scientific focus of medical practice. In Canada, The Royal Commission on Health Care Services, directed by Emmett Hall, concluded that too few physicians were being trained. As a result, during the late 1960's and early 1970's, four new medical schools were opened in response to these concerns. Virtually all medical schools added new subjects like molecular biology, behavioral science and riedical ethics to their curricula. Often there was a reorganization of the basic sciences into new patterns that were not discipline-based. New 'alternative' schools were established and some existing institutions established 'alternative' tracks that differed in some aspects from the traditional ones.

Analyses, however, of the initiatives made over this period reveal that often very little significant change was undertaken and maintained for any length of time. By the late 1970' and early 1980's, most schools had dropped or severely curtailed and modified their alternative tracks (Baldwin, 1992, 148). Or they had reverted entirely to the traditional rigid, limited scientific model developed in the early part of the century. Even the seemingly significant changes that are currently being undertaken at many Canadian medical schools do not necessarily represent a move away from the structures and standards defined by Flexner. Only a very few schools have sought to re-define almost entirely the focus and pedagogy used to teach medicine.

In 1970-71, a survey indicated that ninety percent of 
established medical schools in the United States and Canada had undertaken curricular change in the previous five years (Barzansky, 1992, 24). The extent of change undertaken varied considerably. A 1974 survey indicated that four of the $f$ ifteen Canadian medical schools had completely revised their curricula, while the others made less significant and less substantive adjustments to the existing programs (Kendall and Reader, 1988, 288). Many of the changes involved attempts to blur the distinction that had developed between the basic and clinical science components of traditional medical training. This reflected a concern over the curricular relevance of the basic sciences and laboratory work and the artificial, yet widespread and firmly entrenched, division between the basic science and clinical components of medical training. Most schools introduced courses on psychology, community health and wellness and preventive medicine in attempts to offset the narrowly bioscientific focus of the pre-clinical years (Bussigel at al., 1988, 26). Interdisciplinary instruction, along the lines of the Western Reserve organ-based approach, was regarded as a way to integrate the basic sciences into a more relevant format and reduce the time devoted to basic science in order to relieve what was perceived to be an overly crowded curricula. The flexibility and more balanced curricula that Flexner and the AAMC had called for in the 1920's is clearly seen in the goals of the reform movement of this era. In reality, however, very few schools initiated 
significant philosophic and structural changes along the lines of the innovations undertaken at Western Reserve. Instead, they sought merely to "... inject designated new courses into the curriculum, as if they were intellectual magic bullets that could remedy the perceived dualism and imbalance in medical training" (Fox, 1990, 204). The departments that were responsible for the traditional basic sciences, like anatomy and human physiology, were reluctant to give up any curricular time or emphasis to make room for these new disciplines. The status of these new additions was also much lower than the traditional 'hard' sciences. More often than not little time and effort was extended in their study, in part because the focus of the nation-wide licensing exams remained scientific. Less than half of the American medical schools that had instituted significant curricular changes in terms of curricular integration and expansion of social and ethical awareness by 1974-1975 had retained these reforms a decade later (Bussigel et al, 1988, 27). Medical educators were unwilling or unable to move away from the strictly scientific training that had evolved since the late nineteenth century and the publication of The Flexner Report. The history of the medical profession reveals that allopathic medicine's dominant position in society is in large part based on its connection to science. The importance of homogenous, scientific training to the position of the profession perhaps explains a great deal of its failure to broaden the scope of medical training 
or to alter its basic structure.

In the years immediately following this apparent wave of change and popular support for many of the ideas that had been developing since flexner published his report, many medical schools dropped or drastically altered their reform minded initiatives while those schools who maintained their progressive programs did not appear to be qraduating physicians who differed in any significant way from their peers who were educated in traditional programs. The fate of many of the innovative attempts at reform was a gradual return to the norm of the traditional curriculum (Baldwin, 1992, 148). Undoubtedly there are many reasons for this return to the established curricula. Baldwin asserts that faculty were largely products of traditional learning environments and they were not rewarded nor recognized for their efforts in curricular change which is a difficult, costly and time consuming endeavour (Baldwin, 1992, 148). In general then, attempts to broaden and integrate medical training were gradually abandoned by the mid-1980's (Barzansky, 1992, 30).

\section{McMaster University}

The McMaster University School of Medicine was established in 1969 and many of the new institution's features were characteristic of the social era of medical education reform. The medical faculty at McMaster has continually re- 
assessed and re-adjusted its curriculum since the medical program was started. Unlike other institutions, however, it has maintained, over the years, its commitment to alternative learning structures and methods. Its goal, at the outset, was to develop a radically new form of undergraduate medical education that grew out of dissatisfaction with traditional models of medical education (Neufeld and Barro:s, 1974, 1040). The approach to education and the tools deve op.ad were similar to some of the previously ignored recommendations made by Flexner. Flexner was very critical of the rigidly structured system of medical eiucation that focused on didactic teaching and rote memorization, as well as the lack of social context and concern that had deveioped in traditional medical education.

The primary goal of the new program was to graduate community-oriented "undifferentiated physicians" who would then pursue more specific training after graduation. The program's basic objectives, as explained by the chairman of the education committee in 1976,

. require students to develop knowledge,
ability and attitudes to prepare them for
subsequent training: the ability to
identify problems and define them in
terms of basic mechanisms and be able to
select and make use of appropriate
clinical, behavioural and laboratory
techniques and resources in the community
for solution; the ability to assess their
own educational need and manage their
continuing education; critical attitude
toward research medical practice and the
role of the doctor; and ability to work
effectively in a group (Hamilton, 1976 ,


1191).

The school's founders sought to challenge the sequential learning of basic and then clinical science that has been a cornerstone of the traditional approach to medical education. The traditional format of two years of basic and clinical training established this century was modified somewhat. The McMaster program lasts three full years. During the first two years, students learn in an integrated format in which basic and clinical sciences are studied simultaneously and early clinical exposure is stressed. The final year consists of a traditional clerkship common to all medical programs. The curriculum also seeks to integrate the non-scientific aspects of medicine into the general program of study. The social, community and other non-science considerations are not set apart from the study of the science of medicine. This integration encourages a more holistic understanding of the complexities of health and medicine.

The 'McMaster Philosophy' emphasizes the student and the facilitation of learning rather than the imparting of a particular body of knowledge (Kendall and Reader, 1988, 289). From the outset, the McMaster faculty has combined the learning of basic and clinical sciences through the use of biomedical problems as teaching tools. Neufeld and Barrows, faculty at the medical school, write that

[p]roblem-based learning includes more than simply learning around clinical problems. It represents a fundamental. intellectual process which can be applied 
to any problem $(1974,1044)$.

This problem-based approach to learning developed at McMaster is now well-known and respected by medical educators around the world. In sum, McMaster's educational approach emphasizes self-directed, small-group, problem-based learning that integrates the basic and clinical sciences and encourages early patient contact (Woodward et al, 1990, 79). In some ways McMaster's medical program has challenged elements of the traditional approaches to medical education. Its success at graduating physicians who practice 'better' medicine has been constrained by the broader context of undergraduate medical education, the process of graduate medical education and the structure and culture of the medical profession itself. Today certain aspects of the 'McMaster Philosophy' are being emulated by many institutions in both Canada and the United States in the current wave of reform. This connection to the McMaster innovation will be discussed further in chapter four.

\section{Conclusion}

In the past seventy-five years, both change and stability have characterized the undergraduate medical curriculum. In general, the amount of time devoted to basic sciences and laboratory work has declined somewhat while new subject areas have been incorporated. However, the relative importance of basic science, the discipline based structure and the didactic 
teachıng method have all remained dominant. Therefore, despite the recognition of the flaws in medical education and the widespread dialogue on the need for change, little substantive reform has occurred. The 'social era' of medical school reform has clearly been dominated by rhetoric rather than by action. Currently, another flurry of educational reform is underway that, like all changes made before, purports to overcome the shortcomings of the traditional curricula and to better prepare medical students for their careers as physicians. It is on these changes that the next portion of this thesis will focus. 
Chapter Four

\section{CURRENT REPORHS AT CAMADIAN MEDICAL SCHOOLS}

In the past ten years every English speaking medical school in Canada has undertaken some level of curricular reform. This current movement for reform continues the historic pattern of on-going curricular changc. Although the degree to which each institution has altered its program varies, certain themes and approaches are common amongst all the schools. There is a widespread consensus with respect to both the flaws of the traditional science-based medical programs and the means to redress them. Essentially, all the schools have a similar reform agenda and they differ mainly in the scope and depth of changes undertaken. Several documents and studies have been published over the past twelve years that have contributed to this latest flurry of curricular reform. The most important of these have been the 1984 GPEP Report, that has served as the principle catalyst for current curricular changes, and the 1988 Edinburgh Declaration on Medical Education. In ontario, the Educating Future Physicians for Ontario (EFPO) task force has also contributed significantly to the process of curricular change in that province.

In this chapter, the content of these documents will be explored and common themes and initiatives will be identified. This will provide a framework within which to investigate the 
changes being undertaken at the canadian medical schools. The philosophies and structures of the various programs as well as their stated reasons for change will be discussed in order to present a picture of medical education today in the context of the widespread movement for change. In examining the literature provided by the medical schools, certain common themes emerge. These are reflected in the stated principles of the institutions as well as in the curricular changes being undertaken. The medical schools assert the importance of making medical students more aware of the social context of health and illness, of moving away from discipline-based approaches toward teaching with an integrated systems-based method and of encouraging early patient contact. Finally, the most common strongly asserted goal is the integration of teaching approaches into the curriculum in ways that allow students to gain the skills needed to cope with the changing and growing base of biomedical knowledge. All of the schools studied endorse all or some of these issues in their literature on their curricula, but what is not particularly clear is how the changes undertaken will meet the goals of each of these themes.

The Reform Agenda

In 1984, the AAMC and the AMA produced the report, Physicians for the Twenty-first century, commonly known as The 
GPEP Report. This document has acted as a catalyst for the current wave of reform and has been compared to the Flexner Report in terms of its impact on medical education in both canada and the United states. The panel undertook a wide ranging study of medical education in Canada and the United states in the early $1980^{\prime} \mathrm{s}$. It sought to uncover common areas of concern and to develop strategies to deal with the revealed shortcomings. The Report presents five principal conclusions that are further broken down into twenty-seven specific recommendations for change. The goal of the Report essentially was to stimulate medical schools to review and renew the design of their programs, to implement change and to evaluate their curricula. It suggested ways of meeting the challenges of the future, as understood by the panel.

The introduction to the Report states that the panel

...perceive[d] a continuing erosion of general education for physicians, an erosion that has not been arrested but is instead accelerating. We see continuing pressures to which we must accommodate with vigour and deliberate determination lest critical and irreversible damage is done (GPEP, 1984 XII).

Seven principle pressures are outlined by the panel. The first three deal with the impact that advances in biomedical knowledge and technology will have on the nature of medical practice in the future. The fourth concern recognizes the impact that the psychological, social and economic determinants of health have on health care, while the fifth considers pressure from patient demands for "special medical 
services" and the latest technologies. The final two pressures deal with the impact that reduced health care budgets will have on the practice of medicine.

It is the need to manage these concerns that quides the recommendations made for reforming medical education. Specifically, the five general areas of concern outlined by the report are: the purposes of undergraduate medical education, the nature of the programs themselves, the need for new learning skills, the nature of clinical education, and finally the importance of faculty involvement and support. within each of these general areas, specific recommendations are made that would help medical schools address all of the key issues presented. These recommendations are based on the idea that the goal of medical education is to provide students with a broad, general education that will allow them to specialize in their graduate years.

Like most prior studies, including l'he Flexner keport, the report calls for significant change in the structure and philosophy of medical education and concludes that medical education will "become ircreasingly inadequate unless it is revised" (1984, XII). As Christakis (1995) arques, there is little that is new in the Report and this is in fact acknowledged by its authors themselves. The traditional information-intensive approach to medical education is challenged; the need to broaden the focus of education in the social sciences and humanities is reaffirmed; the need to 
integrate basic and clinical sciences into a cohesive unit is identified; the importance of independent learning skills is stressed vigorously. These are the very same issues that were addressed with the Western Reserve experiment in the 1950's and McMaster's innovative program established in the late 1960's. In fact, Flexner included many similar points in his study. These issues were also the focus of the largely cosmetic changes that were undertaken at many other institutions during the 'social era' of reform in the 1960's and 1970's. The Introduction to the Report acknowledges this in saying,

[a] review of past efforts to modify medical education reveals that most of the problems identified....are not new. Institutions intermittently have changed their curricula, but...little progress has been made toward a fundamental reappraisal of how physicians are educated (GPEP, 1984, xiv).

The main focus of the Report lies in the need to adapt medical education in light of the ever expanding amount of biomedical knowledge and the resulting changes in medical practice. The importance of adjusting medical education to deal with the "rapid advances in biomedical knowledge and technology" is repeated throughout the document. The Report asserts that the goal of undergraduate medical education is to enable students to gain the "knowledge, skills, values and attitudes" that all physicians need to possess to practice medicine effectively. These qualities, particularly the values and attitudes, are not explicitly defined, nor is it clear how 
the panel determined which qualities are the most relevant and appropriate.

In essence, the most important concept presented in the Report, according to the president of the AAMC, is that students must be prepared to learn throughout their careers. The focus of the learning, however, remains largely on the science of medicine, at the expense of its other dimensions. The Report asserts that medical schools must focus their efforts not toward imparting a specific body of knowledge, but rather on enabling students to undertake independent, active and self-directed learning throughout their professional 1 ives (GPEP, 1984, 34). These learning skills are seen as necessary for physicians to maintain mastery of the continually growing and changing base of scientific knowledge: there is no concomitant concern about keeping up-to-date with social, psychological and other non-scientific knowledge. Being able to keep abreast of new scientific information is the driving force behind the current reform agenda. It is this knowledge that has enabled the profession to achieve and maintain control and autonomy in the health care field. It is not surprising, therefore, that organized medicine has focused its medical education reforms, as presented in 'I'he GPEP keport and other current documents, on initiatives influencing medical education that will allow the profession to continue its monopoly and control over scientific knowledge.

The GPEP Report was the catalyst for the renewed interest 
in medical education that has developed over the past ten years. In 1988, the World Federation of Medical Education sponsored an international conference dedicated to developing a platform outlining the needs and goals of medical education on an international level. The resulting document, The Edinburgh Declaration, is a two page declaration in which medical educators pledge their commitment to reforming medical education. There is little that is new in the document, perhaps other than the sense of urgency and immediacy evident in the whole notion of a declaration and the making of pledges. The twelve recommendations listed can be found in most documents calling for the reform of the system of medical education, particularly in the GPEP Report. Concern is expressed over the equitable provision of health care and the importance of ensuring that individual and community needs are met. The need to educate students in a broader, more community oriented fashion and increased emphasis on health and wellness are also stressed. The Declaration is often referred to in the literature written by medical schools on specific curricular changes. The connection, however, between these worthy goals and the actual reforms being implemented is not entirely clear. Moreover, it is unlikely that these goals can be met through the current reform agenda.

More recently in ontario, another project on medical education reform was undertaken. The Educating Future Physicians for ontario (EFPO) project attempted to survey what 
Ontarions feel they need and expect from physicians. The other provinces have not undertaken this type of project. The recently completed project was supported by all five medical schools in the province as well as by the provincial government. The project goal was "to modify the character of medical education in ontario to make it more responsive to the evolving health care needs of Ontario" (EFPO, 1991, 2). The five specific objectives of the project included def ining the health needs of Ontarions, fostering faculty development, developing evaluation mechanisms and supporting the development of new educational programs. EFPO has produced a number of summary documents that present the findings and conclusions of each of the three principal component studies. These include 1) Assessing Societal Health Care Needs and Expectations 2) Preparing the Educators and 3) Assessing student competency. In addition to these summary documents, over twenty working papers were completed on specific issues such as "Views of the chronically Ill" and "Some Views on Native Persons Expectations of Physicians".

In sum, the project compiled information on the health care expectations and needs of various groups and communities within the province, specifically related to physician provided care. Lists of expected roles and competencies are presented within broad areas such as "Physicians as Collaborators", "Physicians as Medical Experts", "Physicians as Communicators (Educators/Humanists/Healers)" Each qrouping 
is concluded with lists of usually seven or eight possible "educational implications" that medical educators should consider when attempting to meet the needs of the community. Each medical school in Ontario provided representatives for the project to oversee curricular change and to encuirage dialogue between the institutions. All the institutions appear to have undertaken reviews of their curricula in order to assess how well their programs deal with the issues raised by the EFPO project.

Specific school initiatives as they relate to EFPo are varied in terms of both the reforms instigated and the scope of the changes made. Also, not all of the changes made result I rom participation in EFPO. Many were initiated independently or prior to the project. Both the Universities of Tororito and ottawa had initiated the process of curricular reform prio: to their involvement in the EFPO project. The curricular changes made at these two schools, however, are certainly the most wide-ranging of the reforms undertaken at the ontario schools in recent years. The sections on "EFPO-Related" activities at each institution focus largely on the establishment of committees to address various issues raised by the project. Queen's University, for example is "now debating whether the university needs a Department of scaial sciences and fiumanities in Medicine" (EFPO, 1991, 85). Some of the reforms also appear quite superficial. Queens, for example, also now offers a single, two hour "lecture on the history of birthing 
methods to medical and nursing students in the same classroom" (EFPO, 1991, 85). While teaching medical and nursing students together is new, the fact that this lecture is optional, oftered only once to each class of medical students and is still considered a significant reform in the teaching of medicine at Queen's demonstrates the limited scope of reform being undertaken. Every school has undertaken some degree of change. Queen's and Western Ontario's initiatives appear to be the more 1 imited, while the Universities of Toronto and ottawa have re-written their curricula. Unfortunately though, as will be discussed further in this chapter, there is little in the way of tangible, established reforms that significantly alter medical education or that address the concerns expressed by the public.

The EFPO project was potentially valuable because it sought to ascertain public perceptions and concerns with physician-provided medical care. Comprehensive surveys, focus groups and interviews were undertaken in order to represent most accurately the views of as many ontarions as possible. The results were then related to educational concerns and strategies. This focus on public opinion is unusual within the literature published by the medical profession on educational reform. Most other reports, The GPEP Report included, have been based on information gathered solely within the profession itself and no attempts were made to include community concerns and opinions. The criticisms presented in 
the EFPO publications tenc to be both greater in number and in severity than is traditionally seen in medical education reform literature. The public clearly has grave concerns over the nature and quality of care that it receives from physicians and holds a broad range of expectations with respect to physician-provided services.

This project provided an excellent opportunity to assess, analyze and explain community concerns with the goal of initiating fundamental change in the education process as well as in the structure and ideology of the profession itself. Unfortunately, but not surprisingly, this approach was not undertaken. The project's recommendations are vague and generalized, virtually mirroring those presented by GPEP and others, and are really too numerous to be useful. So although the approach to this study is somewhat different, the final recommendations are not new and in fact do not even reflect the community and individual concerns raised in the research process itself.

In examining reports advocating reform of medical education, from The Flexner Report in 1910 and the 1932 AAMC study to the recent GPEP Report and The Edinburgh Declaration, a clear pattern emerges. Typically, these reports all identify similar problems with medical education, claim that previous reports have been in large part ignored, argue that reform is urgently needed and advocate changes and corrections that are unmistakably similar. Christakis (1995) has identified twenty- 
four documents released sirice Flexner that follow this pattern and in his article "The similarity and Frequency of Proposals to Reform US Medical Education", he attempts to explain why this pattern of reform without change exists. He argues that the reports have two functions other than their explicit one of improving medical education, "the affirmation of certain core professional values and the self-regulation of the profession" (1995, 711).

In the literature on medical education produced by the profession itself, the vision of the role and position of the medical profession in society is remarkably similar. Traditional scientific medicine has always presented itself as integral to the health and welfare of society and physicians see themselves as the only legitimate providers of health care. The 1993 Pew Report on Medical Education states that "[ $t]$ he health prufessionals are respected because of the special, almost sacred role, they have in matters of 1 ife and death..." (quoted in Christakis, 1995, 708). These sentiments demonstrate the profession's desire for dominance in the health care field and through them the profession seeks to reaffirm its importance and value within society.

The core values espoused in the profession's education reform literature tend to focus on the nature of the profession, its values, mission and role in society. The centrality of the medical doctor to the health of the community is presented as a key reason for undertaking 
educational reform. This assertion attempts to reaffirm the dominant role of the physician just as this very role is being challenged by both the public and other health care professionals as well as by other developments in our health care system. Furthermore, the proposals for dealing with increasing amounts of medical information that make up the medical education reform agenda re-affirm the profession's right both to define and to control what is considered medical knowledge. Control over scientific knowledge has been an integral contributor to the professions's dominant position in our scciety. Therefore, this focus on developing educational strategies for dealing with the ever expanding body of biomedical knowledge, without concomitant pressure to keep up with social, ethical and economic issues, indicates the desire to maintain sole control over scientific knowledge and to ensure the continued centrality of science in medicine, thus perpetuating the profession's dominance.

In addition to this, the idea of promoting a broadly educated "undifferentiated" physician encourages cohesion and uniformity within the profession. This could counteract the splintering effect that increasing specialization is having on the homogeneity of the profession. Furthermore, addressing entrance requirements and determining the qualities that are sought in the atmissions process helps to maintain professional control over entry and access to the profession itself. All of the proposed reforms, therefore, reaffirm the 
profession's self-defined right to self-regulation and direction, while appearing responsive to the challenges and criticisms forwarded by the public, other professions and the state. This becomes clear as the specific reforms undertaken at the English speaking Canadian medical schools are examined in the following section.

\section{Current Medical School Curricula in Canada}

Since the publication of The GPEP Report in 1984 there has been a widespread movement for curricular reform. The extent of change in the curricula varies significantly of ccurse from institution to institution. Many schools have adjusted the goals and principles of their programs. They claim to have incorporated changes in the structure and content of their curricula in order to better educate students for the demands of medical practice in the future. There are four particular themes that are repeatedly advanced in the curricular literature, but the commitment to these issues is not always quite as evident in the actual structure and content of the curricula or in admissions requirements and standards.

The GPEP Report calls for the goal of medical education to be the training of 'undifferentiated' doctors who are able to specialize their training at the post-graduate level. Most medical schools endorse this notion in their mission 
statements or in their statements of goals and principles. The University of Western Ontario, for example, asserts that the goal of its undergraduate medical program is to graduate physicians who "possess the knowledge, skill and attitudes basic to all physicians such that he/she may satisfactorily proceed to further training in any area of the profession" (University of Western Ontario, 1995a, 17). This type of generalized mission statement is common to all the institutions with the phrase "knowledge, skills and attitudes (or values)" appearing in virtually all the literature studied. Most of the institutions do not proceed to define each of these areas specifically, but rather seem to assume that the meaning of each is self-evident.

Some universities (Western, Ottawa, British Columbia) provide explanations of these goals in the form of lengthy lists of attributes and achievements that are to be attained over the period of training. The knowledge component largely refers to the students' grasp of the scientific basis of disease and medical treatment. The University of British Columbia's new curriculum includes seven specific knowledge related goals, all but one relating to scientific aspects of medical practice (University of British Columbia, 1994, 15). In all three cases, some reference is made to understanding the emotional, social and environmental factors influencing health, although the emphasis is still very clearly on the science of treating purely physiological problems. The skills 
component includes clinical skills such as "conducting a full, efficient and appropriate physical examination" (University of Ottawa, 1993, 9) and competence in specitic technical procedures such as venepuncture. In addition, group skills, communication and interpersonal ski $11 \mathrm{~s}$ and competence in self directed learning are included in this category, although with no further discussion. With respect to attitudes and values, emphasis is placed on maintaining 'professional behaviour', demonstrating respect and compassion for patients and families as well as on a broad understanding of "legal, ethical and cultural issues related to clinical practice" (University of British Columbia, 1994, 15). Issues of race, sex and classs are not mentioned in any of the literature.

In addition to a general statement of purpose or intent, most institutions provide more information on the specific: objectives of their programs. The McMaster MD Programme Guide states that

[t]he objectives of the curriculum are for students to develop a broad understanding of medical illness. We expect students to develop not only the knowledge base, but also the skills to use their knowledge optimally. These include problem-solving, critical thinking, and clinical skills. We also expect our students to become competent self-directed learners, and to develop appropriate professional behaviour, both as students and health care professionals $(1995,3)$.

These objectives are typical of those expressed by most faculties of medicine. Virtually all the proqrams scek to 
teach students the skills of self-directed and life-long learning in order to allow them to cope with the continually changing base of biomedical knowledge. However, even Flexner, in his report, called for a move away from passive, fact-laden learning of the sciences with no success. The medical schools' commitment to more active learning is not new and has not been, in the past, successfully implemented. Two of the University of Toronto's four specific goals relate to this theme: "[p]reparing students for the life-long study and practice of medicine and enabling students to initiate and adapt to changes in medicine and health care" (University of Toronto, 1996,6$)$.

coping with new knowledge and technological change is a recurrent theme in all the literature on medical education produced by the profession. Control over the production and dissemination of new scientific knowledge appears to be the most important factor in this current reform agenda. The scientific basis of medicine is continually reinforced and reaff irmed through this emphasis on learning the skills needed to keep up to date and informed with the constant change in biomedical research. The profession gained its dominant position in society by asserting its connection to science and the medical schools' current goals and principles seem to perpetuate this valuable relationship for the profession.

This is reflected in the fact that, in spite of all the rhetoric on the limitations of a narrowly scientific pre- 
medical education, medical schools admission requirements are dominated by science pre-requisites. The G'E'P Report's second major conclusion focuses, in part, on the need to move away from the emphasis on rigidly scientific and prematurely specialized pre-medical training toward encouraqing broader studies less hampered by prerequisites.

Medical faculties encourage students to shape their college programs by requiring specific courses and laboratories and by recommending additional courses that, by implication, will give applicants an advantage. The belief by medical school applicants that medical faculties prefer a narrow science-based preparation is supported by the excessive emphasis many admission committees qive to applicants' scores on the Medical College Admissions Test (GPEP, 1984,4 ).

Although some medical schools have reduced or changed some of their requirements, only McMaster, because it does not require the MCAT, has no specific science prerequisites. less than half of the schools require courses in the social sciences and humanities. All schools, however, state that they encourage applicants to pursue a broad pre-medical academic program and that no specific academic background is rated higher than another. Table 1 indicates the required and recommonded courses for the English speaking medical schools and indicates; whether the Medical college Admissions 'rest (MCA'I) is: required. 
Table 1: Pre-requisites for Admission to Canadian Medical Schools

\begin{tabular}{|c|c|c|c|}
\hline Institution & Required & Recommended & MCAT \\
\hline Memorial & English & & yes \\
\hline Dalhousie & none & $\begin{array}{l}\text { broad study } \\
\text { of physical, } \\
\text { life \& social } \\
\text { sciences }\end{array}$ & yes \\
\hline $\operatorname{MCGi} / 1$ & $\begin{array}{l}\text { biology } \\
\text { general chem. } \\
\text { organic chem. } \\
\text { physics } \\
\text { cell biology } \\
\text { molecular bio }\end{array}$ & & yes \\
\hline ottawa & $\begin{array}{l}\text { biology } \\
\text { general chem. } \\
\text { organic chem. } \\
\text { humanities or } \\
\text { soc. science }\end{array}$ & & yes \\
\hline queen's & $\begin{array}{l}\text { biology } \\
\text { general chem. } \\
\text { organic chem. } \\
\text { physics }\end{array}$ & & yes \\
\hline 'Toronto & $\begin{array}{l}2 \text { lifescience } \\
\text { humanities or } \\
\text { language }\end{array}$ & & yes \\
\hline McMaster & none & & no \\
\hline Western & $\begin{array}{l}\text { biology } \\
\text { general chem. } \\
\text { organic chem. } \\
1 \text { science }\end{array}$ & & yes \\
\hline Manitoba & $\begin{array}{l}\text { English or } \\
\text { French } \\
\text { biochemistry }\end{array}$ & & yes \\
\hline Saskatchewan & $\begin{array}{l}\text { biology } \\
\text { general chem. } \\
\text { physics } \\
\text { English } \\
\text { soc. science }\end{array}$ & & no \\
\hline
\end{tabular}




\begin{tabular}{||l|l|l|l||}
\hline Calgary & none & $\begin{array}{l}\text { biology } \\
\text { general chem. } \\
\text { organic chem. } \\
\text { biochemistry } \\
\text { physiology } \\
\text { calculus } \\
\text { physics } \\
\text { psychology } \\
\text { English }\end{array}$ & yes \\
\hline Alberta & $\begin{array}{l}\text { biology } \\
\text { general chem. } \\
\text { organic chem. } \\
\text { physics } \\
\text { statistics }\end{array}$ & $\begin{array}{l}\text { yes } \\
\text { biology } \\
\text { general chem. } \\
\text { organic chem. } \\
\text { biochemistry }\end{array}$ & yes \\
\hline B.C. & language & \\
\hline
\end{tabular}

Although there is some variation among schools, there is still clearly an emphasis on scientific training as the most acceptable background for the study of medicine. Fewer than half of the schools require some training in the social sciences or humanities and only three have a language: requirement. Moreover, the admissions process tocuses very much on academic achievement and success on the MCA'T. Because grades in the sciences tend to be higher than those in the social sciences and humanities, students with non-science backgrounds are at a disadvantage. Although medical schools; assert that they recognize the need for students with broad and diverse academic backgrounds, success in the scicnces is still the primary requirement for admission to most medical schools. 
The continued use of the MCAT in the admissions process also reaffirms the role of proficiency and knowledge of science in the screening process carried out by the profession. The MCAT, a multiple choice, knowledge-based exam, is divided into four sections: biological science, physical science, verbal reasoning and an essay. The two science-based sections test knowledge of general biology, zoology, general, physical and organic chemistry and physics. The recommended preparation is first and second year university level courses in all of these disciplines. For consideration for admission, most medical schools require a minimum score on each subtest that is above the mean scores of all the tests written. Students must perform well on all the sections and therefore must take courses in all the areas in order to be adequately prepared.

McMaster University, the University of Calgary, Dalhousie University and Memoria] University are interesting exceptions to the pattern of academic requirements. McMaster, one of Canada's most innovative programs in some respects, has no required or recommended courses and does not consider MCAT results in its admissions process. Students with no science background whatsoever can apply and be admitted to the program. Memorial university, Dalhousie University and the University of calgary have no specific science requirements, yet all require the MCAT. Calgary provides a long list of recommended science courses, however, and students without 
traditional science backgrounds "are advised to satisfy specific knowledge deficits during the summer before admissions, by means of conventional or special courses" (University of Calgary, 1995a, 27). Because these institutions require the MCAT, applicants have very little choice but to pursue traditional science courses in their preparation for medical school. It is contradictory not to require science in an effort to encourage students from diverse backgrounds to apply, while at the same time requiring the McAl'. These institutions are seemingly unwilling to move away from medicine's close association with the sciences.

With respect to the actual content and structure of the curricula, medical programs across the country are surprisingly similar. (See Appendix 1 for an example of a typical curriculum.) All schools, except McMaster and Calgary whose programs last three years, of fer four year undergraduate programs that prepare students for post-qraduate training. 'The first two years of medical school focus primarily on learning in academic settings. Although linited early clinical contact is also common, the bulk of the students' time is spent in lectures, laboratory work and small group learning sessions. The clerkship phase generally makes up part of the third year and the entire fourth year of medical school. It is during this period of training that students become fully immersed in the clinical practice of medicine. 'lhey complete rotations of various lengths, usually between four and eight 
weeks, in the basic divisions of medicine: surgery, pediatrics, obstetrics etc. It is during this stage that the students formally become a member of the clinical team. As clinical clerks, the students are responsible for the "diagnosis, investigation and management of patients" (University of Western Ontario, 1995a, 21). This basic curricular structure of two years spent learning each of the basic and clinical sciences is essentially unchanged from the period just following the publication of the Flexner Report. There are some reforms that have, however, been widely instituted to varying, and often limited, degrees and four cominon themes are evident in current programs and curricular changes. The following sections address these four themes.

\section{Interdisciplinary Approaches}

First of all, with respect to the structure of medical education programs, the most widespread and significant change undertaken has been the adoption of integrated, systems-based approaches to teaching. The GPEP Report states that the traditional "discipline and specialty based structure is less effective in promoting the interdepartmental and interdisciplinary work necessary for the design and implementation of a program of general professional education" (GPEP, 1984, 19). Every medical school in Canada has now moved away from the traditional, disciplines-based approach to the 
teaching of the basic sciences during the first two years of training. The disciplines-based approach allowed for littie exchange of information across courses and across years and promoted artificial separation between subject areas (Mann \& Kaufman, 1995, 12). Traditionally, students would spend their first two years concurrently study ing individual subjects like biochemistry, anatomy and physiology.

The new interdisciplinary approach, pioneered at western Reserve and McMaster University, is generally organized around body systems and incorporates all uf these individual subject areas into single units on, for example, "Brain \& Behaviour (10 weeks)", "Skin, Glands \& Blood (9 weeks)" and "Metabolism \& Function (10 weeks)" (Dalhousie, 1995, 13). All lectures: laboratories and tutorial groups focus on different aspects of each unit. At the University of Calgary each body system courso

...deals with the solving of important
and representative patient problems and
provides the information and skills which
are necessary... in each course the
learning of normal and abnormal structure
and function is integrated with learning
the principles of management of patients'
problems (University of calgary. 1995a,
$30)$.

This example is typical of the integrated approach currently or soon to be adopted by all medical schools and is a valuable way of overcoming the sharp division tetween the hasic and clinical sciences that has traditionally existed. It encourages the students to acquire an integrated and relevant 
During their years of academic and clinical training, medical students and young doctors are socialized into the medical profession. They take on the roles and attitudes held by physicians to whom they are exposed throughout their training. This process of professional socialization helps to mold the profession's new recruits into a homogeneous group possessing the beliefs, attitudes and knowledge that serve to perpetuate the power and authority held by the medical profession in our society. However, if the goal of medical education is to train caring and compassionate physicians, then the "brutalizing and dehumanizing" (Fox, 1990, 204) effects of the current system of clinical training must be addressed.

Sociological studies of physicians' clinical training focus on the prevalence of suffering during these years (Light, 1988, 314). Medical journals often feature articles and letters that describe the hardships of internship and residency training that is standard across canada and the United States. Several young doctors have published memoirs describing their own personal experiences during their training. In The House of God, Samuel Shem writes of how he and his peers struggled for their "survival as human beings" as they endured "the cycle of brutality" that was their medical training (1988, no pagination).

In 1987, the ANA officially acknowledged that the "exhausting and often onerous schedule of long hours and no 
knowledge base of the scientific aspects of disease. The focus though remains on physiology and other non-scientific perspectives are not integrated into the courses.

It is important to note that the focus of this reform is clearly on the acquisition of scientific knowledge. The University of British Columbia's curriculum planning committee asserts that this reform is needed because "physicians cannot treat a single patient without a solid and integrated foundation in science" (University of British Columbia, 1994, 41). Only McMaster includes more than the study of science in its interdisciplinary blocks. Each unit at McMaster is studied in reference to three different perspectives- population, behavioral and biological- and all of these are integrated together to meet the objectives of each unit. Other schools focus only on the scientific perspectives in their interdisciplinary units and have developed additional courses in order to address some of the relevant issues relating to the other perspectives.

\section{The 'Art' of Medicine}

The second common theme relates to the inclusion of nonscientific teaching in the curriculum. The University of Toronto, for example, offers two courses that run throughout the two year pre-clerkship stage entitled "The Art and Science of Clinical Medicine and Health" and "Health, Illness and the 
community". This continued separation of the science from other areas of study, with less time and emphasis placed on the 'art' of medicine, perpetuates the dominance of science in medical student training. The types of concerns and criticism raised by the public during the EFPO project most commonly related to how physicians practice the 'art' of medicine. Medical schools today are continuing the trend of placing considerably less emphasis on the human side of medicine and explicitly separating it from the science of medicine. Flexner's recommendations relating to social awareness, attitudes and inter-personal skills continue to be largely ignored in most institutions. Just as in the 1960's and 1970's, educators continue to simply add non-science courses to the curriculum.

Most medical schools express some commitment to fostering an awareness of social issues and concerns as well as encouraging the development of "the qualities of trust and compassion, communication skills, ethical professional conduct and patient advocacy" (University of ottawa, 1995, 30). commonly though, it is not clear how or by what means these objectives are to be met. Often, it appears that the one or two courses on the 'art' of medicine added to the curriculum are supposed to deal with all aspects of medicine that are non-scientific.

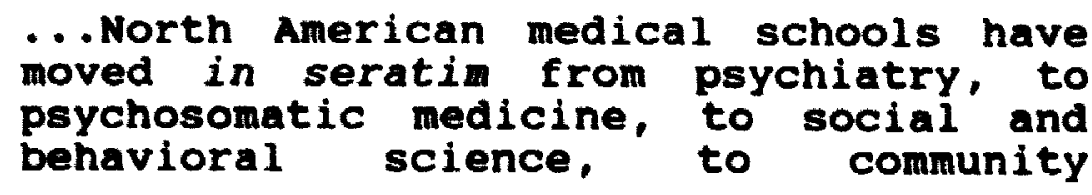


medicire, to bioethics, to the humanities in thrir search for such formulaic solutions (rox, 204, 1990).

At Memorial University, for example, a single course entitled Community Medicine is taken in the first year. It "introduces several subject areas including disease prevention and health promotion, biostatistics, epidemiology, health care delivery and behavioral sciences" (Memorial University, 1995, 32). This is the only formal course covering these areas in the entire four year program. The University of Calgary does not offer a single course or unit that deals with these types of issues. It is these very issues, however, that were raised the most frequently in the surveys carried out by the EFPo group. Medical schools seem unwilling or unable to incorporate a balance between the acquisition of a solid base of scientific knowledge integrated with an equally solid understanding and awareness of the psychosocial issues associated with health and health care,

\section{Early clinical contact}

Over half of the Canadian medical schools have introduced early patient contact and clinical training into their programs. This is the third theme in the current reform agenda. Traditionally, students have spent their first two years of training in strictly academic settings and the third or fourth year clerkship provided the first opportunity to 
deal with patients directly in clinical settings. This lack of clinical contact reinforced the artificial division that existed between the basic and clinical science periods of training. Early clinical contact promotes the integration of these two areas and students are able to see and experience the 'real world' of medicine from the outset of their training.

The University of Toronto asserts that 'patient-centred learning" helps "students develop a perspective on patients that encompasses their biological, psychological and social needs... The emphasis on patient contact allows students to apply basic medical knowledge as they acquire it" (University of Toronto, 1995, 6). Most schools incorporate horizontal units into their programs, like McGill's "Introduction to the Patient" and "Introduction to the Practice of Medicine", through which students are introduced to a variety of clinical settings. For most schools, these are elective units in which students are given some choice. At the University of ottawa, for example, the "Clinical and community skills" unit allows first and second year students to choose from a wide variety of poss:ble clinical experiences ranging from family practice to cardiology to neonatal intensive care. Each student will spend approximately one afternoon a week in her chosen area.

While it is argur 1 that early clinical exposure is an important step toward integrating the basic and clinical sciences as well as toward helping students better learn their 
clinical skills, it also allows for earlier socialization into the role of physician. The University of roronto asserts that 'early involvement in various health care settings exposes students to the roles and responsibilities" of the physician (University of Toronto, 1995, 6). These early clinical experiences begin the process of professional socialization earlier than in the past. In fact, both the University of Toronto and western ontario arrange for each student to spend a full day with a practising pilysician in the first year introductory week. Medical students are now almost immediately placed in the role of physician and this promotes earlier identification with the profession and the professional identity particularly in the absence of alternative curricula.

\section{Problem-Based Learning}

By far the most common theme raised in the documents provided by the medical schools centres on the issue of acquiring the skills needed to deal with an ever expanding and changing body of scientific knowledge. The key reason why schools have undertaken curricular change is the apparent need to teach medical students the skills of self-directed, independent learning that will enable them to access resources and keep current with biomedical advances while they are practising physicians. The traditional information-intensive, passive, lecture-based teaching used by medical schools 
throughout this century has been the focus of extensive criticism from Flexner's period to the present. According to Christakis' survey of documents calling for reform of medical education, the development of new educational methods in order to cope with burgeoning knowledge has been central to almost every major report published this century (1995, 708). The GPEP Report, for example, states that

[t]o keep abreast of new scientific
information and new technology,
physicians continually need to acquire
new knowledge and learn new skill.
throughical students [need] to learn
rather than simply master current
information and techniques. Active,
independent, self-directed learning
requires the ability to identify,
formulate and solve problems... (GPEP,
l984, 9).

Responding to the criticisms of the traditional approaches to teaching is the most common reason presented for the curricular reform currently being implemented. Different teaching methods are being used in attempts to help students cope with new scientific knowledge and this has become the main focus of the renewed programs. The first goal of Dalhousie's new curriculum is to teach students to be "active, independent learners, able to seek out information, to critically analyze it and to apply scientific reasoning to the solution of clinical problems and to use the changing technology of information processing" (Dalhousie University, 1995, 2). Students are being taught the skills that they need to maintain control over new scientific knowledge in order to 
help protect the position and authority of the profession. This widespread emphasis on the need for new learning methods has lead every medical school to incorporate some level of small group and self-directed learning into their programs. The problem-based learning (PBI) approach pioneered at McMaster in the late 1960's has been widely adopted by Canadian medical schools. McMaster's MD Proqramme Guide explains PBL as "using a clinical problem as a stimulus for identifying important concepts for learning" (1995, 18). PBI, should not be confused with problem-solving. The problems and cases studied act as vehicles for learning and applying the concepts of medicine. They also promote the acquisition of skills for accessing necessary information and resources and approaching problems in logical and constructive ways. The goal is not to solve the problem at hand but rather to use it as a base from which to explore a wide range of related issues and concepts. In general, PBL seems to focus almost entirely on scientific or clinical problems. The goal appears to be a deeper understanding of biomedical issues and the development of the skills needed to learn science. It is not clear that other perspectives are addressed in the problem-based tutorial sessions.

At McMaster, $\mathrm{PBL}$ is the essential teaching method employed; there are no formal lectures or laboratories. other schools have incorporated small group PBL sessions into their schedule of lectures and laboratories rather than replacing 
them altogether, although the number of lecture and Iaboratory hours spent has been reduced at all schools. At the University of Toronto, "the weekly schedule consists of five to ten hours of lectures, four hours of laboratories and six hours of PBL" (University of Toronto, 1994, 1). An additional six to eight hours are spent in clinical electives and courses. This type of scheduling is typical of most medical schools. It reflects, on the one hand, the desire to deal with expanding biomedical knowledge through $\mathrm{PBL}$, while at the same time retaining control over the dissemination of a specific body of scientific knowledge through lectures and laboratories.

The 'McMaster Philosophy' and current Reforms

In examining the themes of the current reform agenda, it becomes clear tnat the traditional canadian medical schools are incorporatirg some of the characteristics of McMaster's medical program. The 'McMaster Philosophy' developed at the institution over the past twenty-five years seems to have, at least in part, influenced some of the changes that are currently being undertaken at the other twelve medical schools. As was discussed in chapter three, McMaster's program has in some ways challenged the structure and philosophy of traditional medical education. since its inception, the program has been based on an integrated, problem-based teaching approach that stresses active and self-directed 
learning. There are no scheduled lectures and laboratories and students work in sma!l groups. Early clinical exposure has always been incorporated into the structure of the proqram. In addition, the 'McMaster Philosophy' has always been based on a more community-oriented and holistic approach to medicine and health. The four themes of the current reform aqenda discussed above are clearly closely connected io the program characteristics developed at McMaster.

Although the reforms are similar to McMaster's proqram. the traditional medical schools have not adopted the school's approach in its entirety. Specifically, most. schools have simply added problem-based learning tutorials to their proqram and have not replaced the existing lecture and laboratorybased learning. Moreover, McMaster's integration of nonscientific perspectives on medicine has not been emulated. Population, behavioural and biological perspectives form the basis of every problem investigated by the students (McMaster University, 1995, 12). At the traditional schools, however, the science is still separated from the non-science in different courses and learning experiences. This continued distinction perpetuates the dominance of a limited scientific understanding of health and disease and maintains the primacy of scientific knowledge throughout the training. As previously discussed, McMaster's admissions policies also continues to be somewhat different than those at other institutions. students with no scientific training whatsoever are able to apply and 
less emphasis is placed on grades. The school is also more interested in the students non-academic achievements and skills and as a result the general student profile at McMaster is different than that at the traditional schools (Woodward et a1. 1990,80$)$

Given the current focus on reforms similar to the characteristics of McMaster's curriculum, information on the program's outcomes would provide us with interesting evidence of what might be expected from the current reform agenda. Efforts to evaluate the success of the McMaster program, however, are surprisingly few given the attention and praise that has been directed toward its curriculum. First of all, it is difficult to evaluate in any rigorous way the program's success at meeting its stated goals. The studies that do exist are often limited by selection bias and the absence of control groups and more often than not focus on the students' choices and attitudes immediately following graduation as opposed to when they have completed their training and are working as established practitioners in the community. Dr Thristel Woodward of McMaster's Program Evaluation Group and others have undertaken several studies that have attempted to assess certain aspects of the program's results, but there is little evidence that McMaster graduates are able to better meet the needs and expectations of their patients and communities. One study reveals that graduates regard their experiences at McMaster positively. Graduates endorsed the key features of 
the program such as problem based-learning, self-directed learning and early patient contact; and most would return to McMaster "if they had to do it all over again" (Woodward and Ferrier, 1982, 294). McMaster qraduates have traditionally scored slightly below the national average on the knowledge based multiple choice section of the Medical Council of Canada's licensing examinations while scoring higher on the patient management portion of the exam (woodward, 1984). This discrepancy is likely explained by McMaster graduates inexperience at writing formal examinations. Graduates success at being accepted into the internship and residency programs of their choice is also at levels similar to graduates of other Canadian universities (Woodward and Neuteld, 1978). These types of studies have focused more on demonstrating that McMaster graduates are as qualified as or at least no less prepared than graduates of traditional schools. As such, they do not necessarily provide any evidence that teaching medical students according to the 'McMaster Philosophy' is any better than the traditional approach.

studies of practice patterns and career choices of McMaster graduates indicate that there are some differences between graduates of traditional schools and those from McMaster. Neufeld (1983) and Hamilton (1976) conclude that slightly more McMaster graduates choose family practice and psychiatry, as well as research and academic medicine, than their peers from other institutions. More recently, Ferrier 
and Woodward (1987) found that McMaster graduates were more likely to pursue careers in internal medicine and those in primary care were more likely to hold formal certification in family medicine. They also found that the pattern of a significantly greater level of interest in academic medicine persisted into the mid-1980's. The authors assert that it is difficult to ascertain the reason for these differences and to attribute them to a particular feature of the McMaster program. They note that it is important to consider the profiles of the students admitted to McMaster. McMaster students are in general older, have more experience, lower academic grades and a stronger commitment to educational innovation (Ferrier \& Woodward, 1987, 44). On the other hand, Ferrier (1990) and Glasser et al (1982), however, present results that indicate that medical school curricula "do little to shape [career] preferences" of their students (Ferrier, $1990,347)$

In 1987, Ferrier and Woodward demonstrated that the "nature of practice and time spent on patient care did not differ" between the groups of physicians studied (39). In a further study, however on general practitioners and family physicians published in 1990, woodward et al. claim that McMaster graduates spend more time with their patients and provide more psychotherapy than graduates from other universities. This trend seems to indicate that McMaster graduates may be more likely to provide more thorough and 
holistic care to their patients. The authors assert that this is because of the physicians" Initial interest in attending an alternative medical school as well as the structure and content of the McMaster curriculum itselt. McMaster yraduates, however, are more likely to pursue formal certification in family practice than their peers from other institutions. This formal training in family medicine has been associated with an increased likelihood to provide counselling and psychotherapy and speri sre time per patient (woodward et al, 1989, 897) and authors do not account for this in their 1990 study. It seems premature, therefore, to suggest that McMaster's innovative program is responsible for the ditterences in practice patterns noted. In any case, no measure of quality of care is included in any of these studies and spendinq more time with patients does not necessarily translate into better care (Woodward et al., 1990, 87). Such information can really only be obtained through comparative, in-depth direct studies of physicians' practices and to date nothing of this nature has been published.

While all the studies discussed above are interesting and their results are worthy of further investigation, they do not demonstrate that McMaster has succeeded in meeting its stated goals of producing community-oriented, caring physicians with exceptional commitments to life long learning. The studies undertaken do not endeavour to measure the institution's success at meeting its stated goals and thus it is difficult 
to ascertain whether McMaster has indeed been able to develop a better medical curricula that graduates physicians who can better meet the needs of their patients and communities. In 1982, the medical school undertook a thorough examination of its strengths and weaknesses and it was recognized that while

[f]ollow-up studies of graduates showed
that their performance was comparable to
graduates of other institutlons, there
was a sense that we should be seeing such
distinctive abilities as efficient,
continuing learning, the use of
conceptual and integrative models in
patient care and the critical appraisal
of clinical literature (Neufeld, 1984,
259 ).

In sum therefore, there is little evidence that McMaster, in spite of its innovation and uniqueness, has been successful in graduating physicians who practice medicine in a different and better way. McMaster does admit a more diverse student body, it seems to integrate the science and art of medicine much more than do the other schools and it is more committed to making students aware of social, psychological and community needs. These aspects are certainly commendable and are important in addressing some of the problems with the narrowly scientific, traditional system of medical education. Unfortunately, although similar language and terms are being used, few other schools have actually instituted reforms that accurately reflect these elements of the 'McMaster Philosophy'. Mckaster students, however, are still being socialized into the profession in the same manner as other medical students. The 'hidden curriculum' is not addressed in 
the McMaster program; the clerkship phase and residency training are identical across all schools. Moreover, the content of their education, and importantly which areas are stressed more than others, is not that different from what is taught at all other Canadian medical schools. All graduates must write the same knowledge-based, largely scientific and technical exams in order to practice medicine and this limits the potential impact of McMaster's alternative approaches. It seems, therefore, that McMaster's program endeavours to challenge some of the problematic aspects of traditional medical education. Its effectiveness, however, has been constrained by the broader environment of medical training and the structure and expectations of the medical profession as a whole.

Analysis

In examining current curricular initiatives, there is clearly a widespread movement to change medical school curricula ostensibly in order to meet the demands of our changing society. Certain themes are dominant in this reform agends and are seen in both the literature calling for reform and in the curricular adjustments made by individual institutions. The focus of this chapter to this point has been to outline the principal current concerns and initiatives. The question remains though, is this current reform agenda 
likely to address the long-time problems characteristic of medical education? or will it simply perpetuate the pattern of reform without change that has characterized medical education reform this century?

I would argue that, with the exception of some of McMaster's initiatives, the current efforts at reform do not address the key problems and concerns that have dominated discussions of reform for the past seventy-five years. This is, as Renee Fox stated, "the importance of caring for and caring about patients with competence that is compassionate and compassion that is competent" $(1990,202)$. The current reforms in no way alter the essential structure and content of medical education that are responsible for the problems that we are currently facing. Rather, as has been the case in the past, reformers re-package and re-name the same experiences and information that have always characterized medical education. Problem-based learning in a systems-based format is a new way of teaching the same content that has always been taught. Adding courses in behavioural science, bioethics or the 'art' of medicine in order to create 'social awareness' that in turn somehow automatically promotes humane and compassionate medical care has been tried again and again with little or no success. Encouraging early patient contact, through, for example, orientation days spent with practising physicians, simply exposes students, earlier in their training, to the problematic professional role and models of 
medical practice that are of concern.

Virtually all of the studies of medical education published by sociologists over the past four decades have asserted that the problem with medical education lies in the structure of the training and in the culture of the clinical work (Fox, 1990, 214). Yet, this 'hidden curriculum' is never addressed when medical educators come together to plan or to reform curricula and training programs. Sociologist, Donald Light writes that

[ $t$ ] he structure of a training program-the sequence of experiences, the organization of work, the trainers' background and orientation, the hierarchy of valuesconstitutes a latent curriculum that affects the residents' clinical habits and perspectives as strongly as the manifest curriculum $(1988,313)$.

It has been assumed by medical educators that the manifest curriculum for undergraduate medical education is the instrument that directs the teaching of knowledge, skills, values and attitudes to medical students. The on-going socialization process that is so integral to the development of the attitudes and values that currently characterize the medical profession is entirely ignored by medical educators. As another sociologist, Samuel Bloom, asks,

.. [i]f this educational reform
accomplishes its purposes, so that
medical students experience their first
two years as exciting humanly relevant,
and intellectually stimulating, what kind
of experience do they have after they
enter the third, fourth and post graduate
clinical years? (1988, 302).


During their years of academic and clinical training, medical students and young doctors are socialized into the medical profession. They take on the roles and attitudes held by physicians to whom they are exposed throughout their training. This process of professional socialization helps to mold the profession's new recruits into a homogeneous group possessing the beliefs, attitudes and knowledge that serve to perpetuate the power and authority held by the medical profession in our society. However, if the goal of medical education is to train caring and compassionate physicians, then the "brutalizing and dehumanizing" (Fox, 1990, 204) effects of the current system of clinical training must be addressed.

Sociological studies of physicians' clinical training focus on the prevalence of suffering during these years (Light, 1988, 314). Medical journals often feature articles and letters that describe the hardships of internship and residency training that is standard across Canada and the United states. Several young doctors have published memoirs describing their own personal experiences during their training. In The House of God, Samuel Shem writes of how he and his peers struggled for their "survival as human beings" as they endured "the cycle of brutality" that was their medical training (1988, no pagination).

In 1987, the AMA officially acknowledged that the "exhausting and often onerous schedule of long hours and no 
sleep" that characterizes interns' and residents' on-call schedules can seriously interfere with the quality of care provided to the patients, as well as with the learning opportunities of the physicians-in-training (Fox, 1990, 206). There is, however, widespread opposition from within the profession to changing the structure of clinical training, largely because it is viewed as a right of passage into the profession. The pace and intensity of the work demanded of the house staff as well as the "quasi-military hierarchy" (Light, 1988, 314) that fails to provide the emotional and intellectual support needed by those in training all contribute to the process of desensitizing and dehumanizing young doctors.

Efforts at medical education reform continue to fail to recognize the continuum of education that extends beyond the first two undergraduate years. Integrated, problem-based learning and early patient contact, for example, do not address the hidden curriculum that guides the socialization of students into the profession. The fundamental content and structure of medical education is always left unchanged by curricular reforms, even though change in these areas would better meet the stated goals of the reformers. Maintaining the status quo in these areas, however, helps perpetuate the dominance and autonomy of the medical profession. The system of medical education that has evolved over the past one hundred years, even prior to Flexner, serves to benefit the 
power and control of the profession rather than to produce excellent physicians who can best meet the needs of society. The medical profession achieved its dominant position largely through its connection to the scientific advances of the late nineteenth and early twentieth centuries. The physicians' professional associations (the AMA and CMA) were able to legitimate allopathic medicine through its association with science, while at the same time denigrating those health care practices that were not based on scientific method and knowledge. Control over medical education has contributed to the powerful position occupied by the medical profession in our society. It gives the profession control over the creation and dissemination of the knowledge that enabled physicians to achieve dominance and power in the health care arena in the first place. Control over medical education also ensures that the profession is able to replicate itself with each new generation of physicians. This promotes the homogeneity and commitment to the group that helps ensure the maintenance of professional dominance.

The reforms currently being implemented at Canadian medical schools perpetuate professional control of medical education. They do not appear to compromise or challenge the role that education plays in the maintenance of the profession's powerful position in our society. In essence, most of the reforms focus on new ways of teaching the scientific knowledge that is so integral to the profession's 
dominance. With the exception of McMaster where the centrality of the traditional sciences has been challenged to some degree, the admissions requirements and content of the courses taught during the undergraduate years are still almost entirely oriented toward science. The efforts at introducing some balance between science and other disciplines like the social sciences and humanities are limited. They merely continue the trend of adding token courses in non-science disciplines in attempts to superficially meet the demand for physicians with broad training and understanding of a wide range of issues and concerns.

When The Flexner Report was first published, only those recommendations pertaining to science and to the benefit of the profession's standing in society were implemented. This pattern continues today in the current reform movement. The changes being made at medical schools reinforce the cantrality of scientific knowledge in medical training and practice. No serious attempts have been made to broaden the scope of medical training and knowledge beyond the bounds of science and scientific practice. On the one hand, I would arque that this limits the profession's ability to ment. the changing needs of society. As our understanding of the social, psychological, economic and environmental determinants of health grows, as social structures change and as the level of chronic illness and disease increases, physicians will need to expand their narrowly scientific orientation to remain 
relevant and effective. The EFPO Report demonstrates that individual's expe-tations of physicians are changing and extend well beyond purely scientific and mechanistic medicine. The profession, however, gained its monopoly over medical care through its close affiliation with science and thus appears unwilling to move beyond this connection.

In addition to the explicit focus on maintaining the primacy of science, the reformers failure to acknowledge and address the problems inherent in the medical schools' hidden curricula also serves the interests of the profession, at least in the short-term. No efforts have been made to deal with the impact that current methods of clinical education have on physicians in training in spite of the wealth of information available on the issue. Some medical schools define what attitudes and values their graduates should possess without explicitly indicating how these characteristics are to be learned. No reference is ever made to the structure and culture of clinical work that is the key factor in influencing physicians attitudes, values and practice patterns. The 'brutal' learning environment fostered in clinical settings serves, however, to socialize young doctors into the professional role. clinical training is, according to an article published in the Journal of the American Medical Association (JAMA), in part an elaborate hazing ritual that ensures that physicians learn to identify only with the professional role and adopt common values and 
113

attitudes (Cousins, 1981, 377). This process helps maintain professional dominance and power. The failure to address these issues in the current reform agenda demonstrates the profession's determination not to undermine the critical role that medical education currently plays in perpetuating professional dominance. 
Chapter Five

\section{CONCLUSION}

Samuel Bloom writes in his article "structure and Ideology in Medical Education: An Analysis of Resistance to change" that

$$
\begin{aligned}
& \text { [m]edical education has been changing } \\
& \text { constantly. Nevertheless the } \\
& \text { teaching/learning experience remains } \\
& \text { remarkably similar... How can one } \\
& \text { explain this history of reform without } \\
& \text { change, of repeated modifications of the } \\
& \text { medical school curriculum that alter } \\
& \text { only very slightly or not at all the } \\
& \text { experiences of the critical } \\
& \text { participants, the stucents and the } \\
& \text { teachers? (1988, 295). }
\end{aligned}
$$

The general focus of this thesis has centred on this failure of medical school curricular reform. The yoal was to investigate the history of "reform without change" (Bloom, 1988, 295) that has characterized medical education this century and then to examine current curricular developments in light of this established pattern. In the process of researching and writing this thesis, however, many more questions and research possibilities have emerged. I will use this conclusion, therefore, to present my key findings as well as to discuss issues and questions that would merit further investigation should more work on this topic be undertaken.

The second chapter presented the theoretical framework that quided the investigation and analysis undertaken in the remainder of the project. Freidson's work on professional 
dominance as well as other more recent studies on professional power and control provided a useful framework for the study of medical education reform. Control over the process of medical education, the access to and dissemination of the bio-medical knowledge that sets physicians apart from others, is integral to the maintenance of the profession's dominant position in our society. It is in the interest of the profession that physicians continue to control their own education and that the period of training be used as a tool for professinrai socialization. The education process helps to mold the profession's new recruits into a homogenous group that possesses the beliefs, attitudes and knowledge that serve to perpetuate the power and authority wielded by the profession in our society.

The third chapter presented the history of medical education reform in both Canada and the United States from the late nineteenth century to the early 1980's. This chapter showed that while there has been widespread recognition of shortcomings in the content and process of medical education, attempts at addressing these problems have been sporadic, limited and have had little long-term impact on the education of medical students. The history presented demonstrates that Samuel Bloom's phrase "history of reform without change" is indeed accurate and that the current reform debate is neither new, nor particularly innovative.

The fourth chapter concentrated on current efforts at 
reforming medical education in canada. Much of the work in this chapter is based on the information provided to me by the thirteen Canadian English speaking medical schools. There appears to be a widespread consensus among canadian medical educators as to the flaws of the traditional system of medical education and as to what is required to redress them. It is clear, however, that reform initiatives still focus almost entirely on maintaining the primacy of science in medical training. In addition, no efforts are being made to address the socialization process experienced primarily, but not solely, in clinical settings.

What emerges from these three chapters is a clearer understanding of medical education reform. In sum, current reform efforts, although broader in scope than previous initiatives, continue the pattern of reform without substantive change. The implementation of problem-based learning and integrated courses are in essence new ways of presenting old information. The fundamental connection to science that was so integral to the profession gaining its dominant position is maintained at the expense of other disciplines and the teaching of broader, more holistic approaches to health care. The failure both to acknowledge the hidden curriculum that socializes students into the professional role and to extend reform beyond the undergraduate years, severely limits this current wave of reform. The EFPO project and others clearly show that 
individuals are very much concerned with the quality of care that they receive from their doctors. Yet, the current initiatives, with their narrow focus on science, do little to meet these concerns. Medical education has not yet been reformed and medical schools continue to fail to respond to the needs and expectations of society. The fundamental content, structures and processes remain unchanged and thus the pattern of reform without change continues to this day.

Like most projects, this study of medical school curricula seems to have raised more questions than it has answered. Further research in numerous areas would add considerably to our understanding of the critical issues pertaining to medical education reform. There is clearly a need to study further medical schools as institutional structures and to incorporate the issues of power and process into studies of medical training. This type of investigation would be particularly interesting with McMaster given the alternatives that it has introduced into its curriculum. Attention needs to be paid to the role and interests of the profession, particularly the branch associated with academic medicine, and the connection to the structure and content of medical education. What impact, for example, does biomedical research and the funding it generates have on the education process particularly when medical researchers are often medical educators as well? Moreover, much of the work published on professions is written in an American context. 
There is a need for more studies on the power and dominance of the Canadian medical profession because of the differences that exist between the American and canadian health care systems.

Most of the research published on the socialization of physicians focuses on their years of formal training. What, therefore, are the relative effects on physicians' attitudes and behaviours of professional and non-professional experiences over the course of the life cycle? Socialization is an on-going process and studies should be undertaken that reflect this. As more and more women pursue careers in medicine, there is also a need to investigate further how gender may influence practice patterns and attitudes. It is already clear that women pursue careers in family medicine, pediatrics and psychiatry more often than their male colleagues, that they are more likely to practice in a group setting and that they make less money (Gorham, 1994, 197). The current process of socialization, therefore, may also differentially influence female and male medical students.

If one of the goals of this type of research is to influence the process of medical education, there is a need for dialogue between the medical educators and those undertaking sociological research. Sociological studies of medical education focus on the

interrelationships that exist between the stresses of learning to be a doctor, the ways of coming to terms that medical students... Institutionalize in their 
collective culture, and the problems of emerging from medical training with humane values, caring skills... And yet when medical educators come together to plan or to reform curriculum...., they rarely speak of such matters or take them into account (Fox, 1990, 214).

There is a need to investigate further why the medical profession is unwilling to acknowledge the socialization process and the impact of the hidden curriculum on medical students. Clearly, dialogue between these two groups might help to institute more meaningful reform.

If the goal of medical education is to graduate physicians who are able to meet the needs of the community that they serve in the best possible way, then there is a clear need to reform medical education in this country. As one author stated, "the reforms of the reforms have been reformed" (Kendall \& Reader, 1988, 292) and yet the process of medical education continues to graduate physicians who ar unable or unwilling to provide the kind of care our society wants and needs. It is still too early to know for sure whether the current reforms being undertaken will graduate physicians better able to meet the needs of our changing society. At this early stage, however, it appears that real change has not been implemented and that the current initiatives will not fundamentally alter the practice patterns, attitudes and behaviours of physicians in the next century. 
Appendix one

\section{MCGILL UNIVERSITY CURRICULUN}

DASIS OF MEDICINE (compostilon of Units)

\begin{tabular}{|c|c|c|c|c|c|c|c|c|c|c|c|}
\hline Sept & Oct & Nov. & Dec. & Jen. & Feb. & Mrr. & Apr. & May & June & July & Aus: \\
\hline $\begin{array}{l}\text { Molod } \\
\text { Celly } \\
\text { Thenes } \\
\text { (4w) }\end{array}$ & 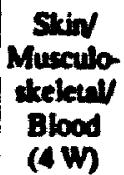 & $\mathrm{G}$ & $\begin{array}{l}\text { Wuid, } \\
\text { tot } \\
\text { nensis } \\
\text { in }\end{array}$ & & of & $\begin{array}{l}\text { Life } \\
\text { Cycle } \\
\text { (3 w) }\end{array}$ & Newo & & 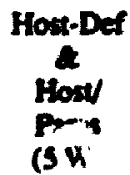 & \multicolumn{2}{|c|}{$\begin{array}{l}\text { Vecuion } \\
\text { Rewevich }\end{array}$} \\
\hline
\end{tabular}

INTRODUCTION TO CLNICAL MEDICNE (ICM)

\begin{tabular}{|c|c|c|c|c|c|c|c|c|c|c|c|}
\hline Sepe & Oct. & Nov. & Dec. & $\operatorname{Jen}$ & Feb. & Mar. & Apr. & My & June & Juby & Aus. \\
\hline \multirow[t]{3}{*}{$\begin{array}{l}\text { Host } \\
\text { Purs } \\
(3 \mathrm{~W})\end{array}$} & \multirow{3}{*}{\multicolumn{3}{|c|}{$\begin{array}{c}\text { Pathobiology } \\
\text { Treatmen \& Prevention } \\
\text { of Disease } \\
\text { (13 W) }\end{array}$}} & \multirow{3}{*}{$\begin{array}{l}\text { IOMA } \\
\text { (4 W) } \\
\text { Clinical } \\
\text { Sciences }\end{array}$} & & $\begin{array}{l}\text { MB } \\
\text { Wh } \\
\text { icine }\end{array}$ & & \multicolumn{2}{|c|}{$\begin{array}{l}\text { lame } \\
\text { (10w) } \\
\text { Surgery }\end{array}$} & $\begin{array}{l}\text { ICM D } \\
(4 \mathrm{~W}) \\
\text { Elect }\end{array}$ & Vection \\
\hline & & & & & Fim & Medicine & & \multicolumn{2}{|c|}{ Emergency Modicine } & \multirow{3}{*}{\multicolumn{2}{|c|}{ Reserich }} \\
\hline & & & & & & $\begin{array}{l}\text { A Med } \\
\text { coillties }\end{array}$ & \multicolumn{3}{|c|}{ Anesthesia } & & \\
\hline \multicolumn{4}{|c|}{ IIPM } & Ethics & & arrics & \multicolumn{3}{|c|}{ Rediology } & & \\
\hline
\end{tabular}

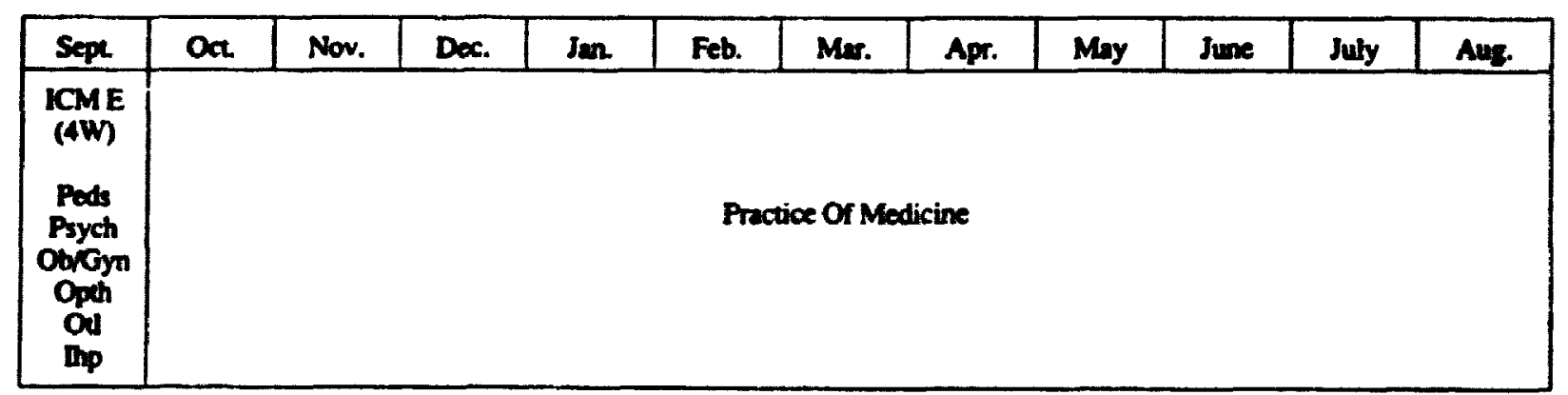

\section{OVERALL ORGANIZATION OF THE CURRICULUM}

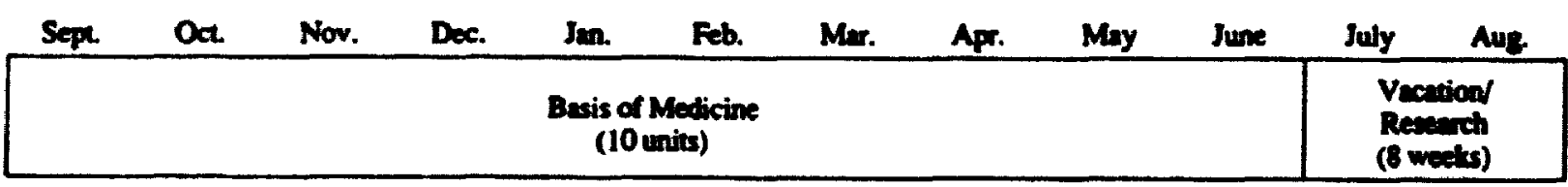

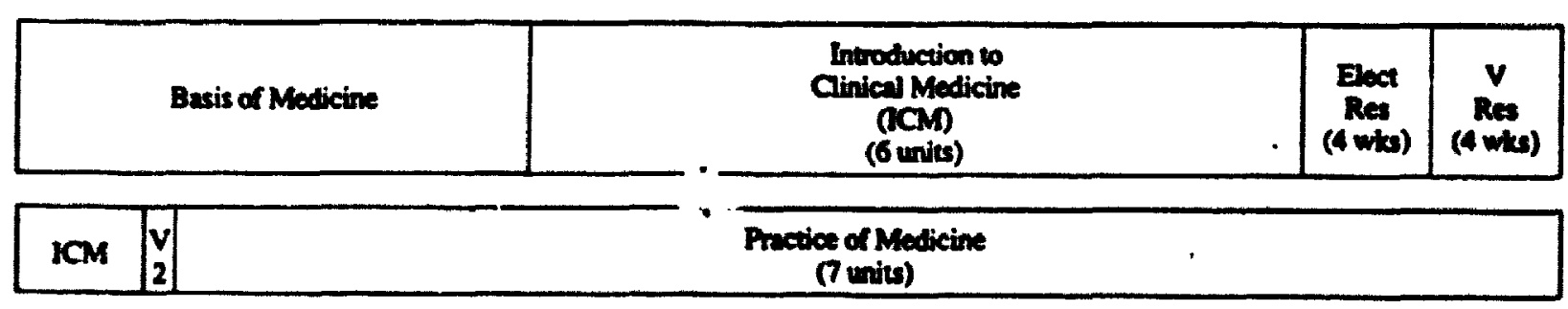

\begin{tabular}{|c|c|c|}
\hline 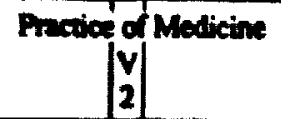 & $\begin{array}{c}V \\
(4 \text { wotets) }\end{array}$ & $\begin{array}{c}\text { Ded w Baica } \\
\text { (5 units) }\end{array}$ \\
\hline
\end{tabular}

Source: Mogill UnIVersity, Appliannt Information, 1995. 


\section{BIBLIOGRAPHY}

Secondary Sources

Atkinson, P. (1983). The Reproduction of the Professional Community. In R. Dingwall \& P. Lewis (Eds.), The Sociology of the Professions (pp. 224-241). London: Macmillan Press.

Baldwin, D. (1992). The Medical Curriculum: Developments and Directions. In B. Barzansky \& N. Gevitz (Eds.), Beyond Elexner (pp. 141-156). New York: Greenwood.

Barbato, A., Frazier, R., Leischner, R. , Gunzburger, L., Loesch, T., Yang, L. (1988). Comparison of Graduates of Regular Curriculum and Unified Basic Science-clinical Curriculum. Journal of Medical Education, 63, 505-514.

Barzansky, B. (1992). The Growth and Divergence of the Basic Science. In B. Barzansky \& $N$. Gevitz (Eds.), Beyond Flexner (pp. 19-34). New York: Greenwood Press.

Brazansky, B., Bussigel, M., \& Grenholm, G. (1988). Innovation Processes in Medical Education. New York: Praeger.

Becker, H., Geer, B., Hughes, E. \& Strauss, A. (1961). Boys in White: student culture in Medical School. Chicago: University of Chicago Press.

Becker, H., Geer, B. Miller, J. (1972). Medical Education. In H. Freeman, S. Levine, \& L. Reeder (Eds.). Handbook of Medical Sociology (pp.191-205). New Jersey: Prentice-Hall.

Beeson, P. (1982). Priorities in Medical Education. Rerspectives in Biology and Medicine, 25, 673-687.

Berliner, H. (1975). A Larger Perspective on the Flexner Report. International Journal of Health Sciences, 5 , 573-592.

Black, S. \& Moore, G. (1994). Project Evaluation. In D. Tosteson S. Adelstein, S. Carver (Eds.), New Pathways to Medical Education: Learning to Learn at Haryard Hedical school (pp. 114-122). Cambridge, Mass.: Harvard University Press.

Blishen, B. (1991). Doctors in Canada: The Chanding vorld of Medical Practice. Toronto: University of Toronto Press. 
Bloom, S. (1979). Socialization for the Physician's Role: A Review of Some Contributions of Research to Theory. In Shapiro \& L. Lowenstein (Eds.), Becoming a Physician (pp. 3-52). Cambridge, Mass .: Ballinger Publishing.

--- (1980). The Process of Becoming a Physician and the Context of Medical Education. In H. Noack (Ed.), Hedical Education and Primary Health Care (pp. 144160). London: Croon Helm.

--. (1985). Institutionalizing Innovation. In A. Kaufman (Ed.). Imolementing Problem-Based Education (pp. 235256). New York: Springer Publishing.

---. (1988). Structure and Ideology in Medical Education: An Analysis of Resistance to Change. Journal of Health and Social Behaviour, 29, 294-306.

Bonner, T. (1989). Abraham Flexner As Critic of British and Continental Medical Education. Medical History, 33, 472-479.

---. (1990). Abraham Flexner and the Historian. The Journal of History and Allied Sciences, 45, 3-10.

Bucher, R. \& stelling, J. (1977). Becoming Professional. London: Sage Publications.

Chappell, N., \& Colwill, N. (1981). Medical Schools as Agents of Professional Socialization. Canadian Review of Sociology and Anthropology, 18, 67-81.

Christakis, N. (1995). The Similarity and Frequency of Proposals to Reform US Medical Education. Journal of the American Medical Association, 6, 706-711.

Coburn, D. (1993). Professional Power in Decline: Medicine in a Changing Canada. In F. Hafferty \& J. McKinlay (Eds.), The Changing Nedical Profession (pp. 92-103). Oxford: Oxford University Press.

--- (1992). Freidson Then and Now: An Internalist Critique of Freidson's Past and Present Views of the Medical Profession. International Journal of Health Services. 22. 497-512.

Coburn, D., Torrance, G., Kaufert, J. (1983) . Medical Dominance in Canada in Historical Perspective: The Rise and Fall of Medicine? International Journal of Health Services, 13, 407-431. 
Colombotos, J. (1988). Continuities in the sociology of Medical Education: An Introduction. Journal of Health and Social Behaviour, 29, 271-278.

Connelly, J. \& White, K. (1992). Redefining the Mission of the Medical School. In J. Connelly \& K. White (Eds.), The Medical School's Mission and Population Health (pp. 1-22). New York: Springer Verlag.

Conrad, P. (1988). Learning to Doctor: Reflections on Recent Accounts on the Medical School Years. Journal of Health and social Behaviour, 29, 320-332.

Conrad, P., \& Schneider, J. (1981). Professionalization, Monopoly, and the structure of Medical practice. In $p$. Conrad \& J. Kern (Eds.), The Sociology of Health and Illness (pp. 155-164). New York: St. Martin's Press.

Cousins, N., (1981). Internship: Preparation or Hazing. Journal of the American Medical Association, 246, 21412144 .

Ebert, R. (1975). The Social Era of Medical Education. In w. Gibson (Ed.), Health Care, Teaching and Research (pp. 111-125). Vancouver: University of British Columbia Press.

Ebert, R. \& Ginzberg, E. (1988). The Reform of Medical Education. Health Affairs, 2, 5-38.

Ferrier, B. (1990). Choosing a Career Within Medicine: Do the style and structure of Medical Schools Make a Difference? Yedical Teacher, 12, 345-348.

Ferrier, B., Woodward C. (1987). Career Choices of McMaster University Graduates and Contemporary Canadian Medical Graduates. CMAJ, 136, 39-44.

Ferrier, B., Woodward, C., Cohen, M., Williams, A. (1996). clinical Practice Guidelines: New-to-Fractice Family Physicians" Attitudes. Canadian Family Physician, 42 , $463-467$.

Fox, R. (1989). The Sociology of Medicine. Englewood Cliffs, New Jersey: Prentice-Hall.

--. (1990). Training in Caring Competence. In H. Hendrie C. Lloyd (Eds.), Educating Competent and Humane Physicians (PP. 199-216). Indiana: Indiana University Press. 
Freidson, E. (1970). Profession of Medicine. New York: Dodd, Mead \& Co.

---. (1981). Professional Dominance and the ordering of Health Services. In P. Conrad \& J. Kern (Eds.), The Sociology of Health and Illness (pp. 184-197). New York: st. Martin's Press.

-- (1986). Professional Powers. Chicago: University of Chicago Press.

Gidney, R., Millar, W. (1994). The Reorientation of Medical Education in Late $N$ ineteenth Century ontario. Journal of the History of Medicine and Allied Sciences, 49, 52-78.

Gorham, D. (1994). No Longer an Invisible Minority: Women Physicians and Medical Practice in Late TwentiethCentury North America. In D. Dodd \& D. Gorham (Eds.), Caring and Curing: Historical Perspectives on Homen and Healing In canada. (pp. 183-211). Ottawa: University of ottawa Press.

Haas, J. \& Shaffir, W. (1978). The Professionalization of Medical students: Developing Competence and A Cloak of Competence. Symbolic Interaction, 1, 71-87.

Hafferty, F. (1991). Into the Valley: Death and the Socialization of Medical students. New Haven; Yale University Press.

Hafferty, F. \& McKinley, J. (1993). Cross Cultural Perspectives on the Dynamics of Medicine as a Profession. In F. Hafferty \& J. McKinley (Eds.), The Changing Medical Profession (pp. 210-226). Toronto: oxford University Press.

Hamilton, J. (1974). The McMaster Curriculum: A Critique. British Medical Journal, 1, 1191-1196.

Haug, M. (1988). A Re-Examination of the Hypothesis of Physician Deprofessionalization. The Millbank Quarterly, 66, 48-55.

Hendrie, H. (1990). The Ideal Physician. In H. Hendrie C. Lloyd (Eds.), Educating competent and Humane Physicians (Pp. 72-80). Indianapolis: Indiana University Press.

Holmes, D. Kaufman, D. (1994). Tutoring in Problem-Based Learning: A Teacher Developing Process. Medical Education, 28, 275-283. 
Huddle, T. (1993). Basic Science and The Undergraduate Medical Curriculum. Perspectives in Biology and Medicine, $36,550-564$.

Hudson, R. (1992). Abraham Flexner in Historical

Perspective. In B. Barzansky \& N. Gevitz (Eds.), Beyond Elexner (pp. 1-18). New York: Greenwood Press.

Hurst, J. (1992). The Bench and Me. New York: Igaku-Shoin.

Hunt, A. (1991). Medical Education, Accred tation and National Health, Lansing, Michigan: Michigan University Press.

Jamous, H. \& Peloille, B. (1970). Professions or SelfPerpetuating Systems? In Jackson (Ed.), Professions and professionalization. Cambridge: Cambridge University Press.

Johnson, T. (1972). Professions and Power. London: Macmillan.

Jonas, S. (1978). Medical Mystery. New York: w.w. Norton.

Kane, R., Wooley, F., \& Kane, R. (1973). Toward Defining the End Product of Medical Education. Journal of Medical Education, 48, 615-625.

Kaufman, M. (1976). Amercian Medical Education: The Formative Years, 1765-1910. Westport, Conn.: Greenwood.

Kendall, P. \& Reader, G. (1988). Innovations in Medical Education of the $1950^{\prime}$ 's Contrasted with Those of the 1970 's and $1980^{\prime} \mathrm{s}$. Journal of Health and Social Behaviour, 29, 279- 293.

Klass, P. (1987). A Not Entirely Benign Procedure: Four Years as a Medical student. New York: Putnam.

Kurtz, R. \& Chalfant, H. (1984). The Sociology of Medicine and Illness. Toronto: Allyn Bacon.

Larson, M. (1977). The Rise of Prefessionalism. Berkeley: University of California Press.

Liederman, D. \& Grisso, J. (1985). The Gomer Phenomenon. Journal of Health and Social Behaviour, 26, 222-232.

Light, D. (1979). Uncertainty and Control in Professional Training Journal of Health and Social Behavior, 20 , $310-322$. 
-- (1988). Toward a New Sociology of Medical Education. Journal of Health and Social Behaviour, 29, 307-322.

Light. D. \& Levine, S. (1988). The Changing Character of the Medical profession: A Theoretical overview. The Millbank Quarter1y, 66, 10-27.

Lippard, V. (1974). A Half Century of American Medical. Education. New York: Josiah Macy.

Lowenstein, L. (1979). The structure and Function of Graduate Medical Education. In E. Shapiro $\mathrm{L}$. Lowenstein (Eds.), Becoming A Physician (pp. 95-112). Cambridge, Mass.: Ballinger.

Mandin, H., Harasym, P., Eagle, C. \& Watanabe, M. (1995). Developing a "Clinical Presentation" Curriculum at the University of Calgary. Academic Medicine, 20, 186-192.

Mann, K. \& Kaufman, D. (1995). A Response to the ACME-TRI Report: the Dalhousie Problem-Based Learning Curriculum. Medical Education, 29, 13-21.

Martinez-Burrola, N., Klepper, D., \& Kaufman, A. (1985). Admissions into a Problem-Based Curriculum. In $A$. Kaufman (Ed.), Implementing Problem-Based Medical Education (pp. 164-179). New York: Springer Publishing.

Mckinley, J. (1988). Introduction. The Millbank ouarterly, $66,1-9$.

Merton, R., Reader, G., Kendall, P. (1957). The Student Physician: Introductory studies in the sociology of Medical Education. Cambridge, Ma.: Harvard Univerisity Press.

Mitchinson, w. (1991). The Nature of Their Bodies, Toronto: University of Toronto Press.

Moore-West, M., \& Booker, J. (1985). The Primary Care Curriculum: Educating for Change in Medicine. In 25th Annual conference on Kedical Education (Pp. 323-328). Chicago: University of Illinois Press.

Moore-West, M., Regan-Smith, M., Dietrich, A, Kollisch, D. (1990). Innovations in Medical Education. In $H$. Hendrie c C. Lloyd (Eds.), Educating competent and Humane Physicians (pp. 128-173). Indiana: Indiana University Press. 
Moore-West, M., O'Donnel1, J. (1985). Program Evaluation. In A. Kaufman (Ed.), Imolementing Problem-Based Medical Education (Pp. 180-206). New York: Springer Publishing.

Naylor, C. (1986) . Private Practice, Public Payment:

canadian Medicine and the Politics of Health Insurance. Kingston: MCGill-Queen's University Press.

Navarro, V. (1988). Professional Dominance or

Proletarianization?: Neither. The Millbank Quarterly. $66,55-68$.

Neufeld, V., \& Barrows, H. (1974). The McMaster Philosophy: An Approach to Medical Education. Journal of Medical Educatini, 49, 1040-1050.

Neufeld, V. (1983). Adventures of an Adolescent: Curriculum Changes at Mckaster University. In C. Friedman, E. Parcel (Eds.), The New Bielogy and Medical Education (pp. 256-270). New York: Josiah Macy Jr. Foundation.

Olson, J. (1987). The McMaster Philosophy: A Student's Perspective on Implementation. Medical Education, 21. 293- 296.

Pelligrino, E. (1987). The Reconciliation of Technology and Humanism: A Flexnerian Task 75 Years Later. In C. Vevier (Ed.), Elexner 75 Years Later. Maryland: University Press of America.

Rachlis, M. \& Kushner, C. (1994). Strong Medicine: How to Save Canada's Health Care System. Toronto: Harper Collins.

Rogers, D. (1988). Clinical Education and the Doctor of Tomorrow: An Agenda for Action. In B. Gaste1, \&. Rogers (Eds.), Proceedings from the Josiah Nacy Jre. Foundation National Seninar on Medical Education. New York: Josiah Macy Jr. Foundation.

Schimdt, H., Dauphinee, D., Patel, V. (1987). Comparing the Effects of Problem-Based and Conventional curricula in an International Sample. Journal of Medical Education, 62, 305-314.

Siegrist, J. (1980). Integrating Medical sociology into the Medical Curriculum. In H. Noack (Ed.). Medical Education and Primary Health Care (pp. 294-305). London: Croon Helm. 
Shapiro, M. (1978). Getting Doctored: Critical Reflections on Becoming a Physician. Kitchener, ont.: Between the Lines.

Shem, S. (1988). The House of God. New York: Dell.

Spaulding, W. (1989). Aspects of Canadian Medical Education. CB.iH, 6, 179-183.

Stelling, J., \&ucher, R. (1979). Professional cloning: The Patterning of Physicians. In L. Lowenstein, \& $\mathrm{E}$.

Shapi ro (Eds.), Beconing a Physician (Pp. 139-162). Cambridge, Mass.: Ballinger Publishing.

Stoeckle, J. (1988). Reflections on Modern Doctoring. The Hilibank Quarterly, 66, 76-89.

stritter, F., Mattern, W. (1983). Thoughts About the Medical School Curriculum. In C. Friedman, E. Parcel (Eds.). The Nen Biology and Medical Education (pp. 228270). New York: Josiah Macy Jr. Foundation.

Tuohy, C. (1982). Smoke and Mirrors: Professional Ideology and Symbolism in Health Policy. In B. Squires (Ed.), Proceedings of the conferences on Health in the 80 's and 90 's and its Impact on Health services. Montabello, Quebec: Council of ontario Universities.

--- (1993). Health Policy and Fiscal Federalism. Presented at Conference on the Future of Fiscal Fderalism, Queen's University.

Turner, B. (1995) . Yedical Power and Social Knowledge. London: Sage Publications.

williams, G. (1980), Hestern Reserve's Experiment in Medical Bducation and Its outcome. New York: Oxford University Press.

Wilson, M., Smythe, C. (1983). Medicine. In C. McGuire, R, Foley, A. Gorr, \& R. Richards (Eds.), Handbook of Health Professions Education (pp. 20-50). Washington: Jossey-Bass .

Wolinsky, F. (1988). The Professional Domiance Perspective, Revisited. The Millibank ouarterly, 66, 33-45.

Woodward, C., Ferrier, B. (1982). Perspectives of Graduates Two to Five Years After Graduation from a Three-year Medical School. Jeurnal of Medical

Education, 57, 294-303. 
Woodward, C. (1984). Summary of McMaster Medical graduates' Performances on the Hedical council of Canada

Examination. Hamilton, Ont.: McMaster University.

--- (1984). Summany of McMaster Medical Graduates" Performance on the Medical council of Canada Examination. Hamilton, Ont.: McMaster University.

Woodward, C., Ferrier, B., Cohen, H., Goldsmith C. (1990). A Comparison of the Practice Patterns of General Practitioners and Family Physicians Graduating from McMaster and other Ontario Medical Schools. Teaching and Learning in Medicine, 2, 79-88.

\section{Reports}

Association of American Medical Colleges. (1984). Physicians for the menty-First century. Washington: AAMC.

--- (1925). The Report on Medical Education. New York: AAMC.

Educating Future Physicians for Ontario. (1991). Part 2 Overview and synthesis: What People of Ontario Need and Expect from their Physiciang. Toronto: EFPO.

Flexner, A. (1910). Medical Education in the United Stater and Canada: A Report to the carnegie coundation for the Advancement of Teaching. New York: The Carnegie Foundation.

\section{Primary sources}

Dalhousie University, Faculty of Medicine. (1995) . COPS curriculum: student orlentation Manual. Hal ifax: Dalhousie University.

-- (1993). The cops Curriculum. Halifax: Dalhousie University.

--- (1991). Report of The Curriculun Task Force. Haifiax: Dalhousie University. 
McMaster University. (1995) . uD Programme General Guide. Hamilton: Mcmaster University.

-- (1996). Underaraduate calendar 1996-1997. (pp.46-51). Hamilton: McMaster University.

McGill University. (1995). Medicine 2995-96. Montreal: McGill University.

--- (1996). Eaculty of Medicine: Information for Applicanta. Montreal: McGill University.

Memorial University of Newfoundland. (1995). Faculty of Medicine Calender. (pp.268-285). St.John's: Memorial University of Newfoundland.

Memorial University of Newfoundland, Faculty of Medjcine. (1996). The Renomed Underaraduate Curriculum. st.John's: Memorial University of Newfoundland.

Queen's University. (1995). Faculty of Medicine: Calendar 1995-1996. Kingston: Queen's University.

University of Alberta. (1996). Leading the Way: University of Alberta Calendar. (pp.47-49, 200-205). Edmonton: University of Alberta.

University of British Columbia. (1994). Renewal of the MD Programin at the University of British Columbia: Report of the strategic planning committee on curricular Revision. Vancouver: University of British Columbia.

--. (1996). Calendar 1996/97. (pp.247-268). Vancouver: University of British Columbia.

University of Calgary, Faculty of Medicine (1995a). Infornetion Brochure. Calgary: University of Calgary.

--- (1995b). Faculty of Medicine Calendar. Calgary: University of Calgary.

University of Manitoba, Faculty of Medicine. (1995) Applicant Inforation Bulletin. Winnipeg: University of Manitoba.

University of Manitoba. (1996) . General calendar 1996-1997. (pp. 302-311). Winnipeg: University of Manitoba.

University of Ottawa, Faculty of Medicine. (1991). Princinleg of the Nay Underaiaduate Curriculum. Ottawa: University of Ottawa Press. 
--. (1995). Medicine: Undercuraduate Studies 1995-1997. ottawa: University of ottawa.

University of Saskatchewan. (1995) . 1995-1996: Univeraity Calendar. (pp.226-233). Saskatoon: University of Saskatchewan.

University of Toronto, Faculty of Hedicine. (1994). The Renewed Undercraduate curriculum. Toronto: University of Toronto.

---. (1996). MD Admissions. Toronto: University of Toronto.

University of Western Ontario. (1995a). Medicine. London: University of Western Ontario.

-- (1995b). Medicine at Nestern. London: University of Western ontario.

-- (1996). Western 1996-1997 Academic calendar. (pp. 7882 ). London: University of Western Ontario. 

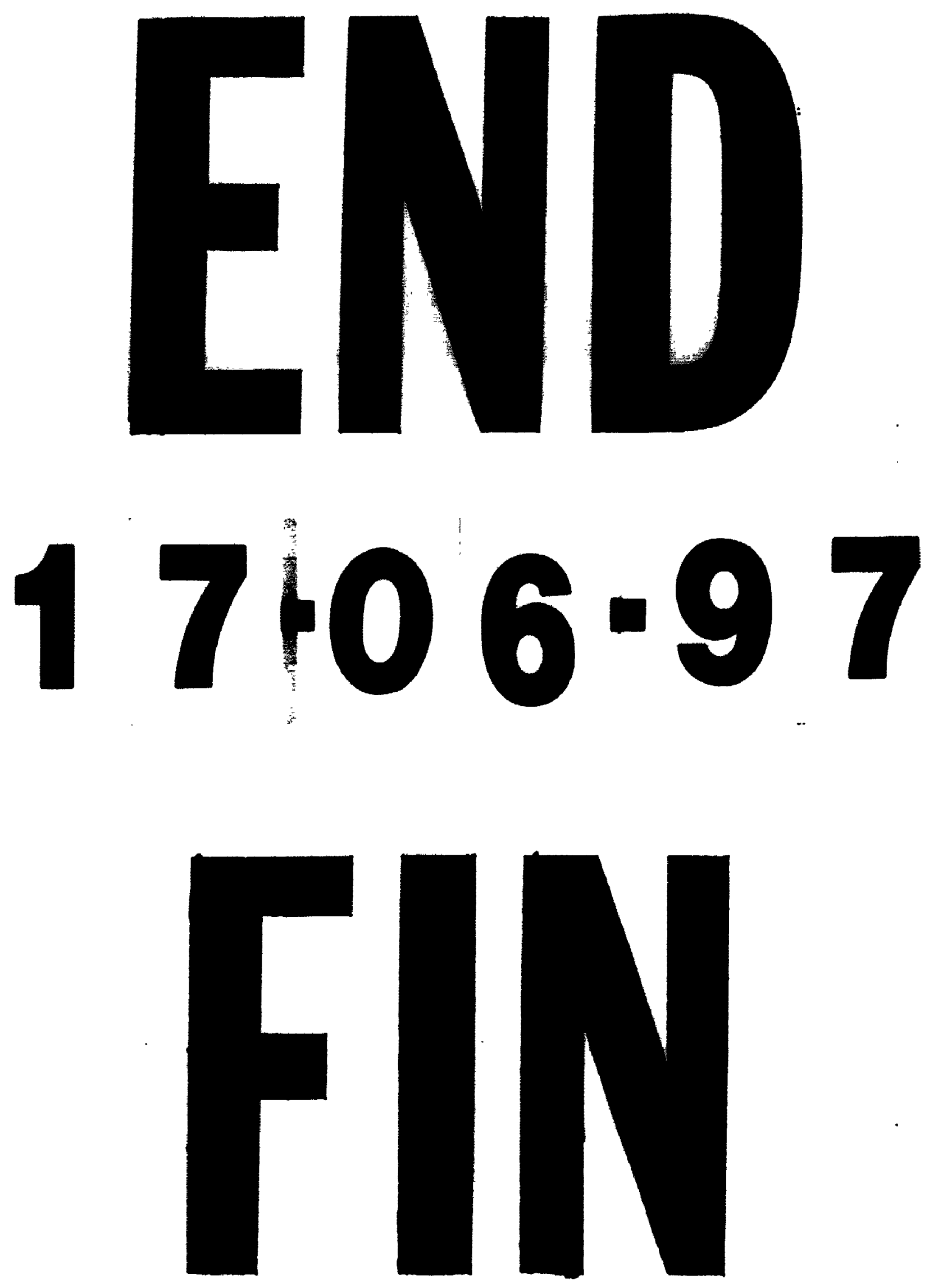